\title{
Exogenous Neural Precursor Cell Transplantation Results in Structural and Functional Recovery in a Hypoxic-Ischemic Hemiplegic Mouse Model
}

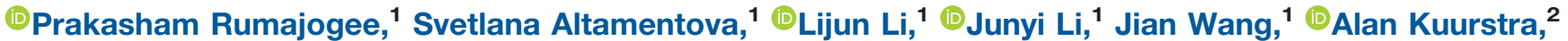 \\ Mohamad Khazaei, ${ }^{1}$ Stephanie Beldick, ${ }^{1,3}{ }^{1}$ Ravi S. Menon, ${ }^{2}$ Derek van der Kooy, ${ }^{3}$ and ${ }^{\circledR}$ Michael G. \\ Fehlings ${ }^{1,4}$
}

https://doi.org/10.1523/ENEURO.0369-18.2018

${ }^{1}$ Division of Genetics and Development, Krembil Research Institute, University Health Network, Toronto, ON M5T 2S8, Canada, ${ }^{2}$ Centre for Functional and Metabolic Mapping, Robarts Research Institute, the University of Western Ontario, London, ON, N6A 5B7, Canada, ${ }^{3}$ Institute of Medical Science, University of Toronto, Toronto, ON M5S 1A8, Canada, and ${ }^{4}$ Department of Surgery, University of Toronto, Toronto, ON, M5S 1P5, Canada

\begin{abstract}
Cerebral palsy (CP) is a common pediatric neurodevelopmental disorder, frequently resulting in motor and developmental deficits and often accompanied by cognitive impairments. A regular pathobiological hallmark of $\mathrm{CP}$ is oligodendrocyte maturation impairment resulting in white matter (WM) injury and reduced axonal myelination. Regeneration therapies based on cell replacement are currently limited, but neural precursor cells (NPCs), as cellular support for myelination, represent a promising regeneration strategy to treat $\mathrm{CP}$, although the transplantation parameters (e.g., timing, dosage, mechanism) remain to be determined. We optimized a hemiplegic mouse model of neonatal hypoxia-ischemia that mirrors the pathobiological hallmarks of CP and transplanted NPCs into the corpus callosum (CC), a major white matter structure impacted in CP patients. The NPCs survived, engrafted, and differentiated morphologically in male and female mice. Histology and MRI showed repair of lesioned structures. Furthermore, electrophysiology revealed functional myelination of the CC (e.g., restoration of conduction velocity), while cylinder and CatWalk tests demonstrated motor recovery of the affected forelimb. Endogenous oligodendrocytes, recruited in the CC following transplantation of exogenous NPCs, are the principal actors in this recovery process. The lack of differentiation of the transplanted NPCs is consistent with enhanced recovery due to an indirect mechanism, such as a trophic and/or "bio-bridge" support mediated by endogenous oligodendrocytes. Our work establishes that transplantation of NPCs represents a viable therapeutic strategy for $\mathrm{CP}$ treatment, and that the enhanced recovery is mediated by endogenous oligodendrocytes. This will further our understanding and contribute to the improvement of cellular therapeutic strategies.
\end{abstract}

Key words: Cerebral palsy; hypoxic-ischemia; myelination; neural precursor cells; oligodendrocytes; white matter injury

\section{Significance Statement}

Cerebral palsy (CP) is one of the most common pediatric neurodevelopmental disorders, affecting $>17$ million people worldwide. Current treatment options for CP are largely restricted to rehabilitative approaches that alleviate and mitigate symptoms. This paper demonstrates, in a mouse model that mimics several pathobiological and clinical features of $\mathrm{CP}$, that the transplantation of exogenous neural precursor cells (NPCs) represents a viable therapeutic option for the treatment of CP. Exogenous NPCs transplanted into the corpus callosum resulted in repair and regeneration of white matter (WM) injury and functional recovery. Restoration of the WM injury was consistent with an indirect effect mediated by the exogenously transplanted NPCs. Therefore, this work supports the use of stem cells for CP treatment. 


\section{Introduction}

Cerebral palsy (CP) is an overarching term encompassing a variety of movement disorders that manifest early in childhood. CP patients often show simultaneous impairments in motor control, cognition, memory, learning, and/or other neurologic functions (Graham et al., 2016). There are numerous underlying causes of $\mathrm{CP}$, including events that occur pre-, peri-, and/or postnatally, which may act independently or be linked together ("multiple-hit hypothesis"). Risk factors for CP include preterm birth, maternal/fetal infection or inflammation, hypoxia/ischemia, and genetic predispositions (Rumajogee et al., 2016).

A common pathologic cause of CP is periventricular leukomalacia (PVL), which mainly results from hypoxiaischemia and infection/inflammation (Khwaja and Volpe, 2008). The periventricular region is highly vascularized and prone to injury following cerebral blood flow alteration, occasionally leading to hemorrhage (De Reuck, 1971; Volpe, 2009a,b). The unilateral injury to one brain hemisphere by PVL results in hemiplegic $C P$, characterized by the paralysis (hemiplegia) or weakening (hemiparesis) of one side of the body. PVL frequently affects white matter (WM) structures, resulting in failed myelination of axons connecting different brain regions and leading to cognitive and motor deficiencies (Coq et al., 2016; Back, 2017; Sampaio-Baptista and Johansen-Berg, 2017). WM injury is characterized by astrogliosis, microgliosis, and hypo-myelination, due to oligodendrocyte (OL) maturation disruption (Khwaja and Volpe, 2008; Volpe, 2009a,b; Buser et al., 2012; Back and Miller, 2014).

Despite general advancements in health care research, the incidence of $\mathrm{CP}$ remains unchanged (Colver et al., 2014). Current treatment options for CP are limited and include therapeutic hypothermia (Thoresen, 2015), surgical interventions (Graham et al., 2016), and rehabilitative strategies (Faulkner et al., 2013), all of which have demonstrated partial functional improvements in CP patients (McAdams and Juul, 2016). However, no therapies have been effective in repairing the injured WM. From a repair

Received September 21, 2018; accepted September 24, 2018; First published October 22, 2018.

The authors declare no competing financial interests.

Author contributions: P.R. and M.G.F. designed research; P.R., S.A., L.L., and J.L. performed research; J.W., R.S.M. contributed unpublished reagents/ analytic tools; P.R., S.A., L.L., J.L., A.K., M.K., and S.B. analyzed data; P.R., M.G.F. wrote the paper; P.R., S.A., L.L., J.L., J.W., A.K., M.K., S.B., R.S.M., D.v.d.K., and M.GF., revised paper; M.G.F. funding acquisition.

The authors wish to thank the Kids Brain Health Network as well as the Ontario Brain Institute for project support. Dr. M. G. Fehlings acknowledges support from the Halbert Chair in Neural Repair and Regeneration. Dr. R. S. Menon acknowledges support from the Canada Research Chairs Program and Brain Canada.

Acknowledgments: We thank Miranda Bellyou and Dr. Alex Li for the MRI experiments (Dr. Menon's lab), as well as Dr. Mohamad R. Khazaei for in vitro staining. We thank Dr. Paul Bradshaw and Dr. Tim Worden for critical and editorial support.

Correspondence should be addressed to Dr. Michael G. Fehlings, FRCSC, E-mail: Michael.fehlings@uhn.ca.

https://doi.org/10.1523/ENEURO.0369-18.2018

Copyright (C) 2018 Rumajogee et al.

This is an open-access article distributed under the terms of the Creative Commons Attribution 4.0 International license, which permits unrestricted use, distribution and reproduction in any medium provided that the original work is properly attributed. and regeneration perspective, stem cell therapy appears to be a promising strategy. However, the optimal parameters of transplantation (e.g., cell type, location, timing, dose) are yet to be determined.

In this study, we optimized a neonatal hypoxicischemic $(\mathrm{HI})$ hemiplegic mouse model based on the Rice-Vannucci model (Rice et al., 1981). The brain injury generated was restricted to the hemisphere ipsilateral to the carotid occlusion, and predominantly affected the subcortical and periventricular WM, striatum/thalamus, hippocampus, and cerebral cortex (Vannucci and Vannucci, 2005). Impaired myelination is a central feature of this model (Clowry et al., 2014; Rumajogee et al., 2016).

After $\mathrm{HI}$, we transplanted exogenous neural precursor cells (NPCs) to examine their ability to repair and regenerate the injured WM and restore function. NPCs are a promising cell type due to their fate-restriction and ability to differentiate into neurons, astrocytes, and OLs. Studies from our lab have shown that transplanted NPCs can differentiate into OLs and promote myelination (KarimiAbdolrezaee et al., 2010; Ruff et al., 2013b). Therefore, the potential for NPCs to differentiate into myelinating OLs and circumvent hypomyelination observed in CP represents an attractive therapeutic option (Faulkner et al., 2013; Ruff et al., 2013a).

We transplanted NPCs into the corpus callosum (CC), the main interhemispheric commissure of the brain composed of densely bundled WM tracts (Richards et al., 2004), as this structure is known to be significantly damaged in children with CP (Davatzikos et al., 2003; Panigrahy et al., 2005; Kulak et al., 2007; Ho et al., 2013; Andronikou et al., 2015), as well as after neonatal $\mathrm{HI}$ in animal models (Sheldon et al., 1996; Skoff et al., 2001; Shrivastava et al., 2012). The CC is more involved in premotor and motor coordination than previously suggested, and impaired somatosensory inputs lead to motor deficiencies (Kulak et al., 2007; Paul et al., 2007; Coq et al., 2016), which supports the CC as a target for regeneration.

We used a range of techniques including histology, immunohistochemistry, MRI, electrophysiology, and behavioral testing, to examine the pathology of the $\mathrm{HI}$ model and to explore the potential of exogenously transplanted NPCs to restore areas of WM and neurobehavioral function.

\section{Materials and Methods}

\section{Animal use}

Experimental procedures, animal use and care were approved by the Animal Care Committee at the University Health Network in accordance with the policies and procedures outlined by the Canadian Council of Animal Care. $\mathrm{C} 57 \mathrm{BI} / 6$ mice were housed under controlled conditions (12-h light/dark cycles, $24^{\circ} \mathrm{C}$ temperature, and fed ad libitum with automatic watering). The day of birth was defined as postnatal day (PND) 0.

\section{Study design}

At PND7, male and female mice were subject to either a sham surgery (sham) or hypoxia-ischemia surgery $(\mathrm{HI})$. After surgery, all mice were exposed to hypoxic conditions. At PND21, NPCs were transplanted into sham (sham + NPC) 

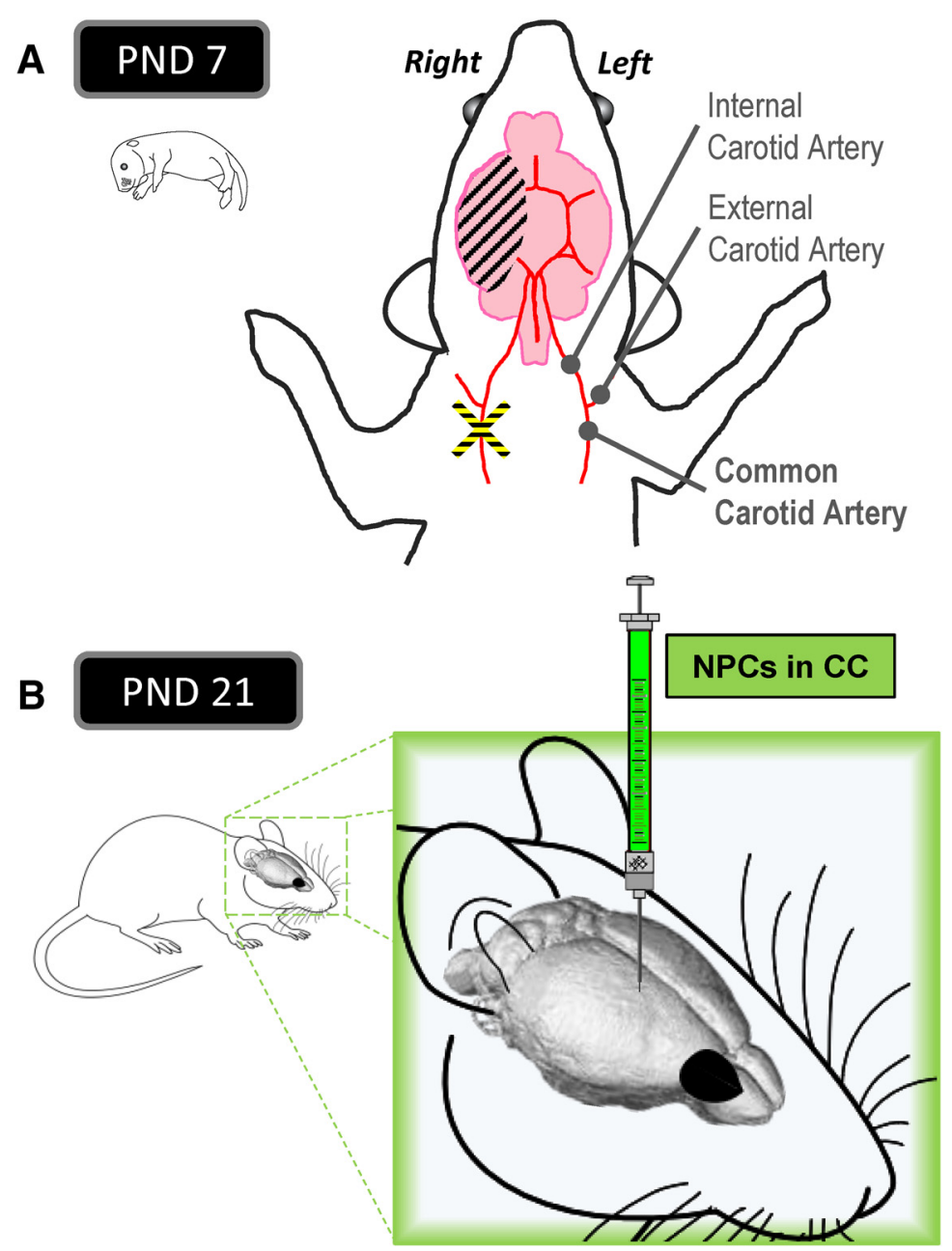

Figure 1. Experimental design. A, The right common carotid artery of postnatal day 7 mice was permanently occluded (ischemia). After $2 \mathrm{~h}$ of recovery with the dam, the pup was exposed to $8 \% \mathrm{O}_{2}$ air (hypoxia). $\boldsymbol{B}$, At postnatal day 21 , NPCs were transplanted in the corpus callosum.

and $\mathrm{HI}(\mathrm{HI}+\mathrm{NPC})$ mice. Mice that did not receive NPC transplant received vehicle (sham + vehicle and $\mathrm{HI}+$ vehicle). Mice were randomly selected from each experimental group from several litters, and a number of outcome measures were performed, including immunostaining and histology, electrophysiology, MRI, and behavioral testing (cylinder rearing test and the CatWalk test).

\section{Hypoxia-ischemia model, based on the Rice-Vannucci model}

The Rice-Vannucci model is known to generate variable injury, which can be described as mild, moderate, or severe (Rice et al., 1981; Palmer et al., 1990; Balduini et al., 2000; McQuillen et al., 2003; Okusa et al., 2014). In this study, we optimized the experimental conditions by standardizing the surgical procedure and reducing the hypoxia time to obtain a consistent mild $\mathrm{HI}$ injury as detailed in Fig. 1. Mild $\mathrm{HI}$ injury ensured impairment of the $\mathrm{CC}$ without causing complete destruction of the structure and allowed for direct comparisons between mice that did and did not receive NPC transplantation. We used PND7 pups based on histologic similarities with human fetuses at 32-34 weeks of gestation (Johnston et al., 2005; Coq et al., 2016).

\section{Ischemia surgery}

Each PND7 pup was anaesthetized with a mixture of $5 \%$ isoflurane and $95 \%$ oxygen for $1.5 \mathrm{~min}$. The pup was then placed in the surgical area where it was maintained under $2.5 \%$ isoflurane. An incision was made on the right side of the neck at the shoulder level. For pups in the $\mathrm{HI}$ group, the right common carotid artery was isolated from the surrounding tissues, exposed using a fine hook, and permanently cut with a cauterizer (Change-A-Tip, Fine Science Tools). The sham surgery group, which functioned as the control for this experiment, was exposed to the same procedure as the $\mathrm{HI}$ surgery group except no carotid occlusion was performed. All pups then received one drop of bupivacaine hydrochloride (Marcaine, 5mg/ $\mathrm{ml}$, Hospira/Pfizer) applied to the surgery site as an analgesic. The incision was closed using surgical suture (Sofsilk, Covidien), and the pups recovered under a lamp. The total surgical procedure took 5 min $\pm 30 \mathrm{~s}$. However, due to the suggestion that isoflurane has a neuroprotec- 
tive effect (Chen et al., 2011), the pup was kept under $2.5 \%$ up to $6.5 \mathrm{~min}$ to maintain consistency. The total exposure time was therefore adjusted to $8 \mathrm{~min}$. The pups recovered in a cage under a heating lamp, returned to the dam once all surgeries were completed, and were allowed to recover for $2 \mathrm{~h}$.

\section{Hypoxia procedure}

After the 2-h recovery period, each pup was placed in a 250-ml ventilated bottle and immersed in a heated water bath $\left(36.5^{\circ} \mathrm{C}\right)$. After $15 \mathrm{~min}$ of acclimatization, hypoxic air (8\% oxygen/92\% nitrogen) was delivered and maintained for $45 \mathrm{~min}$ (flow rate of $2 \mathrm{l} / \mathrm{min}$ ). After exposure to the hypoxic environment, the pups were exposed to $15 \mathrm{~min}$ of normoxia before they were returned to their dam. The temperature and duration used for this procedure was based on preliminary work demonstrating that longer hypoxia times or higher temperatures led to more severe injury, occasionally producing the total absence of the CC. The death rate was $9 \%-10 \%$ after the hypoxia procedure. Animals $(<2 \%)$ with a moderate or severe injury (no visible CC; $>30 \%$ liquefied cavity) were excluded from the study.

\section{Adult NPC transplantation}

Adult NPCs were isolated from transgenic adult mice expressing yellow fluorescent protein (YFP) [strain 129$\mathrm{Tg}$ (ACTB-EYFP)2Nagy/J; The Jackson Laboratory] according to a previously described protocol (Tropepe et al., 1999). Briefly, the subependymal zone of the mouse forebrain was dissected and processed. Cells were dissociated and cultured in uncoated flasks. The nonadherent neurospheres were passaged weekly for 3-6 passages. NPCs were prepared in serum-free medium at a density of $5 \times 10^{4}$ live cells $/ \mu$ l.

NPCs were transplanted in the CC of PND21 mice, which corresponds to a 2-yr-old child from a developmental perspective (Semple et al., 2013). In line with past studies, the injury is already observed at P21. Lesions are already noticeable as soon as $50 \mathrm{~h}$ after insult (Rice et al., 1981; Johnston et al., 2005; Vannucci and Vannucci, 2005; Hagberg et al., 2015; Rumajogee et al., 2016). Starting $2 \mathrm{~d}$ before transplantation (PND19), Sandimmune was given subcutaneously twice daily $(10 \mathrm{mg} / \mathrm{kg}$, Sandimmunel.V., Cyclosporine concentrate, $50 \mathrm{mg} / \mathrm{ml}$, Novartis). For the sham and $\mathrm{HI}+$ NPC groups, mice at PND21 were anaesthetized with isoflurane ( $5 \%$ for $90 \mathrm{~s})$, then weighed and shaved. Next, the mice were maintained under $2.5 \%$ isoflurane in a stereotaxic frame (David Kopf Instruments) while the transplantation sites were prepared. The skin was disinfected, and an incision was made above the midline. The skull was cleaned with a sterile saline solution, and the Bregma point was located for use as an anatomic reference. Using Mastercarver Micro-Pro, two holes were drilled on the right (ipsilateral injury) side (+1 mm lateral/rostral and $+1 \mathrm{~mm}$ lateral/ caudal), and the meninges were punctured with a fine needle. After the puncture, isoflurane was lowered to $1.5 \%$. Pulled glass needles, mounted on a $5-\mu l$ syringe (Microliter Syringe, Hamilton) connected to a micro-pump system (Micro4, World Precision Instruments), were used to inject $2.5 \mu \mathrm{l}$ cell suspension into the CC (anterior site 1-mm depth; posterior site $1-\mathrm{mm}$ depth $/ 10^{\circ}$ angle) at a rate of $250 \mathrm{nl} / \mathrm{min}$. A waiting period of $1 \mathrm{~min}$ before injection and $2 \mathrm{~min}$ after injection was found to reduce the potential for leaks. After this procedure, the skin was sutured and each mouse was given subcutaneously 0.1 $\mathrm{ml}$ of $0.9 \%$ saline solution, $0.1 \mathrm{ml}$ buprenorphine $(0.048$ $\mathrm{mg} / \mathrm{kg}$, Comparative Medicine and Animal Resources Centre, McGill University), and Sandimmune (10 mg/kg).

The pups were weaned, and food supplement was added to the cage (Kitten Milk Replacer; PetAg). For the following $2 \mathrm{~d}$, animals were given buprenorphine and Sandimmune twice daily subcutaneously. Afterward, mice were given Cyclosporine in drinking water $(0.08 \mathrm{mg} / \mathrm{ml} ; 20$ $\mathrm{mg} / \mathrm{ml}$ solution, Chiron Compounding Pharmacy) and were frequently monitored.

\section{Structural outcomes}

\section{Tissue preparation}

At specific time points ( $4 \mathrm{~d}$ and 2, 4, 6, 9, 11, 13, and 19 weeks), a subsection of animals was deeply anaesthetized and transcardially perfused with $0.1 \mathrm{M}$ PBS followed by $4 \%$ paraformaldehyde/0.1 M PBS, pH 7.4. Brains were then extracted, postfixed for $4 \mathrm{~h}$, cryoprotected, embedded, and frozen as previously described (Ruff et al., 2013b). $20-\mu \mathrm{m}$ coronal sections from bregma -2.5 to $+1.2 \mathrm{~mm}$ were collected on Superfrost + Slides (Fisher Scientific) on the cryostat and stored again at $-80^{\circ} \mathrm{C}$ for later use.

\section{Immunostaining and histology}

Frozen sections were thawed in double-distilled water, spread using fine brushes, and air-dried before being rehydrated in PBS. For immunostaining, a blocking step was performed for $1 \mathrm{~h}$ at room temperature (RT) in a solution of $2 \%$ fetal bovine serum and $0.1 \%$ Triton $X-100$ in 0.1 M PBS. The primary antibodies used were mouse anti-MBP $(1: 1000$, Covance, SMI-99P) for myelin; mouse anti-GFAP (1:1000, Millipore, MAB3402) for astrocytes; rabbit anti-Olig2 (1:400; Millipore, Ab9610) for oligodendrocytes; mouse anti-APC (CC1, 1:250, Abcam, Ab16794) for mature oligodendrocytes and astrocytes; Cy3-conjugate mouse anti-Nestin (1:500, Millipore, MAB353C3) as an NPC marker; mouse anti-NeuN (1:500, Millipore, MAB377) for neurons; guinea-pig antiDoublecortin (DCX, 1:400, Millipore, AB2253) for immature neurons; and mouse anti-chondroitin sulfate (CS-56, 1:1000, Abcam, ab11570) for chondroitin sulfate proteoglycan sulfated in position 6 . The brain sections were incubated overnight at $4^{\circ} \mathrm{C}$ with the primary antibodies diluted in a blocking solution. Double-staining was done using 2 primary antibodies with no cross-reaction. The following day, the sections were washed three times in $0.1 \mathrm{M}$ PBS (washes of 5, 10, and $15 \mathrm{~min}$ at RT) and incubated with the suitable secondary antibodies (1:400 in 0.1 M PBS for $1 \mathrm{~h}$ at RT): Alexa Fluor 568 IgG (Life Technologies, anti-rabbit A11011; anti-mouse A11031; anti-chicken, A11041) and Alexa Fluor 647 lgG (Life Technologies; anti-mouse, A21235; anti-rabbit, A21244; anti-guinea-pig, A21450). DAPI (1:1000, Life Technologies, $D 3571$ ) was also used to stain the A-T rich DNA regions. The sections were then washed three times in $0.1 \mathrm{M}$ PBS (washes of 5, 10, and $15 \mathrm{~min}$ at RT). Slides were mounted in Mowiol (Calbiochem), covered with coverslips, and kept at $4^{\circ} \mathrm{C}$. For histologic analysis, Luxol fast blue (LFB) and he- 
matoxylin and eosin (H\&E) staining was performed as previously described (Goto, 1987).

\section{Quantification}

Researchers that participated in the quantification of structures were blinded to the identity of the mice. Eight sham mice, $15 \mathrm{HI}+$ vehicle mice, and $16 \mathrm{HI}+\mathrm{NPC}$ mice were included in these analyses.

Stereological assessments of the CC volume, as well as the transplanted NPCs $\left(\mathrm{YFP}^{+}\right)$and the Olig2 ${ }^{+}$cells counts, were done using the Cavalieri estimator (Stereo Investigator, MBF Bioscience). The transplanted NPCs were counted within the whole injection site in the CC. The Olig2 ${ }^{+}$cells were counted within the CC in a virtual coronal slice of $\sim 3-\mathrm{mm}$ thickness, which covers both anterior and posterior transplantation sites ( $\sim 24 \mathrm{sec}-$ tions). The $\mathrm{YFP}^{+} / \mathrm{Olig}^{+}$were also evaluated, as well as the area and volume of the CC.

Mature $\left(\mathrm{Olig}^{+} / \mathrm{CC}^{+}\right)$and immature $\left(\mathrm{Olig2} 2^{+} / \mathrm{CC}^{-}\right)$oligodendrocytes were counted in the CC. Three pictures per animal were taken using a confocal microscope (magnification 20×) from 12-15 coronal sections covering both transplantation sites $( \pm 1 \mathrm{~mm}$ rostrocaudally from bregma). Similarly, the counting of $\mathrm{YFP}^{+}$cells (NPC) which were also positive for GFAP, DCX, $\mathrm{NeuN}^{+}$, or Nestin was performed on 6-9 coronal sections per transplanted sham and $\mathrm{HI}$ animal.

Additionally, neurons $\left(\mathrm{NeuN}^{+}\right)$were counted in the cortex. One picture of the primary motor cortex (PMC) and two pictures of the somatosensory cortex (SSC) of each hemisphere were taken from 9-12 coronal sections per animal. Landmarks were used to maintain consistency between coronal sections. The thickness of the PMC and SSC were also assessed. The brain hemispheres and hippocampus areas were evaluated, using Stereo Investigator, on 18 coronal LFB/H\&E brain sections per animal, which provided additional data for cortex thickness and CC area.

\section{Electrophysiology}

Before decapitation and dissection of the brain, mice were deeply anesthetized with sodium pentobarbital $(60$ $\mathrm{mg} / \mathrm{kg}$, i.p.) and underwent transcardiac infusion with cold $95 \% \mathrm{O}_{2} / 5 \% \mathrm{CO}_{2}$ saturated sucrose-substituted artificial cerebrospinal fluid (aCSF). aCSF contained (in $\mathrm{mM}$ ): sucrose 210; $\mathrm{NaHCO}_{3} 26 ; \mathrm{KCl} 2.5 ; \mathrm{CaCl}_{2} 1 ; \mathrm{MgCl}_{2}$ 4; $\mathrm{NaH}_{2} \mathrm{PO}_{4}$ 1.25; and D-glucose 10. Eight serial $400-\mu \mathrm{m}-$ thick coronal slices of the brain containing the CC were obtained on a Leica vibrating microtome VT1200S (Fig. 9A; Li et al., 2016). Isolated CCs were severed the midpoint and separated into left and right halves. These separated CCs were incubated in identifiable positions on a mesh in oxygenated aCSF containing (in $\mathrm{mM}$ ): $\mathrm{NaCl} 125$; $\mathrm{NaHCO}_{3} 26 ; \mathrm{KCl}$ 2.5; $\mathrm{CaCl}_{2}$ 2; $\mathrm{MgSO}_{4}$ 1.3; $\mathrm{NaH}_{2} \mathrm{PO}_{4}$ 1.25; and D-glucose 10 , at RT with $95 \% \mathrm{O}_{2}-5 \% \mathrm{CO}_{2}$ for at least $1 \mathrm{~h}$ before electrophysiological recording.

Compound action potentials (CAPs) were acquired using suction electrodes for both stimulating and recording, as previously described (Li et al., 2016). CAPs recorded from the CC provided the information regarding myelinated axons as demonstrated by the fast conduction velocity (CV) first peak (peak1). In contrast, nonmyelinated axons were assessed using the $\mathrm{CV}$ of the second peak (peak2). The recordings were performed in a $0.5-\mathrm{ml}$ bath with a 2.8-mm distance between two electrodes continuously perfused at $1 \mathrm{ml} / \mathrm{min}$ with aCSF oxygenated by $95 \% \mathrm{O}_{2} / 5 \% \mathrm{CO}_{2}$ (Fig. 9B). The stimulating pulses of 0.1 -ms duration and varying amplitude $(0.01 \sim 1.5 \mathrm{~mA})$ were applied via the PSIU6 stimulus isolation unit Grass S88 dual-channel stimulator (Grass Technologies). CAPs were recorded with an Axoprobe 1A amplifier (Molecular Devices/Molecular Devices). The signals were processed using pClamp8 software and DigiData $1320 \mathrm{~A}$ at a $100-$ $\mathrm{kHz}$ sampling rate (Molecular Devices/Molecular Devices). Data analysis was performed offline using Clampfit10 after filtering the signals with a $10-\mathrm{kHz}$ low-pass filter.

\section{Magnetic resonance imaging}

MRI was performed on 6 sham mice, $11 \mathrm{HI}+$ vehicle mice and $10 \mathrm{HI}+$ NPC mice. Mice were imaged on a 9.4-T small animal MRI scanner equipped with a $30-\mathrm{mm}$ millipede volume coil (Agilent, Palo Alto). High-resolution in vivo anatomic images were obtained using a 3D TrueFISP pulse sequence (FOV: $16 \times 16 \times 16 \mathrm{~mm}^{3}$; data matrix: $128 \times 128 \times 128$; TR/TE: $6.0 / 3.0 \mathrm{~ms}$; flip angle: $30^{\circ}$ ) yielding an isotropic $125 \mu \mathrm{m} 3 \mathrm{D}$ image. Image processing was performed using Advanced Normalization Tools (ANTs) and the Insight Segmentation and Registration Toolkit (ITK). Intensity inhomogeneity was corrected using the N4 algorithm (Tustison et al., 2010), and intensity normalization was performed by histogram matching (Nyul et al., 2000). Images were smoothed by a curvature driven flow algorithm (50 steps of step size 0.0001 were performed on ITK's finite difference solver), allowing sharp ventricle boundaries to be preserved (Sethian and Sethian, 1999). The ventricle volume was then measured using a connected threshold region growing algorithm (Johnson et al., 2017).

\section{Functional outcomes}

Eight sham mice, $15 \mathrm{HI}$ + vehicle mice, and $16 \mathrm{HI}+$ NPC mice completed the functional tests detailed below. The researchers who performed the functional assessments were blinded to the identity of the mice.

\section{The cylinder test}

This cylinder test was used to assess preferential forelimb use. Each mouse was placed in a clear plastic cylinder and its rearing activity was recorded for five consecutive minutes with a camera placed beneath the apparatus. The placement of the whole palm on the cylinder wall demonstrates the use of that forelimb for body support. The use of the right $(R)$ unaffected versus left $(L)$ affected forelimb was calculated as a percentage of total contacts: $R /(R+L) \times 100$. Additionally, the forelimb used first in a rearing sequence was calculated.

\section{The CatWalk test}

The CatWalkXT (v10.6, Noldus Information Technology) was employed to measure walking performance. Each animal walked freely through a corridor on a glass walkway illuminated with beams of light from below. A successful walking trial was defined as having the animal walk at a steady speed (no stopping, rearing, or groom- 

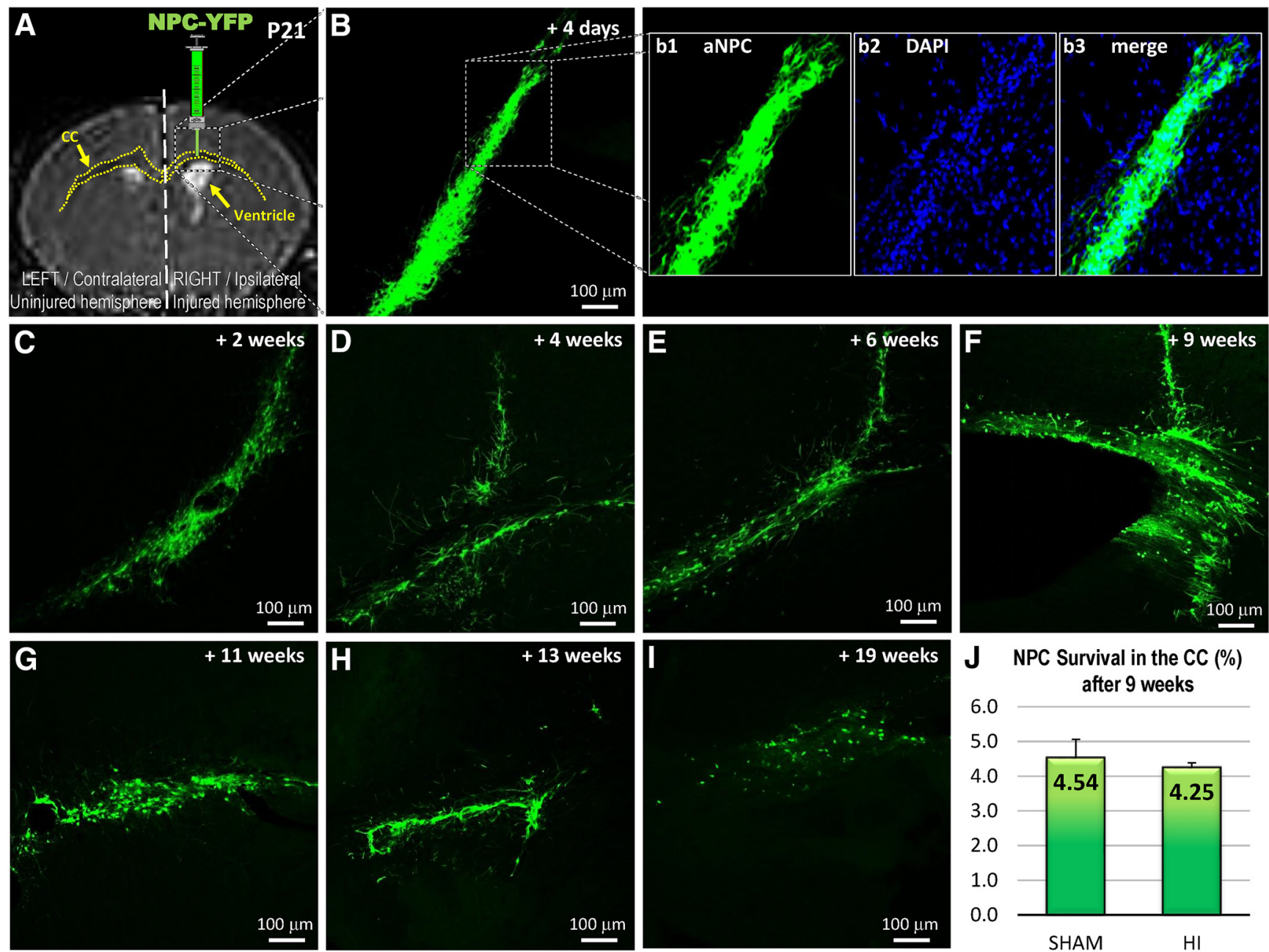

Figure 2. Transplanted NPCs survive, migrate, differentiate morphologically, and integrate within the corpus callosum. At P21, injury is visible by $\mathrm{MRI}$ and includes the thinning of the CC (outlined in yellow) and a right ventriculomegaly. $\boldsymbol{A}$, NPCs were transplanted in the right/ipsilateral/injured CC at PND21. $\boldsymbol{B}-\boldsymbol{I}$, The NPCs migrated and spread through the CC. Their morphology changed from a round-type (in vitro) to a fibroblast-like cell type and, subsequently, to a cell with multiple processes. I, Transplanted NPCs (green) are counterstained by DAPI (blue; b1-b3). The NPCs survived $>19$ weeks after transplantation. $\boldsymbol{J}$, The survival rate was similar in the HI and sham animal after 9 weeks.

ing), and three to five successful trials were collected per animal. The footprints were recorded using a camera positioned below the walkway, and footprint classification was manually corrected to ensure accurate readings (Chen et al., 2017). CatWalkXT software was then used to analyze several gait parameters including swing speed $(\mathrm{cm} / \mathrm{s})$, stride length $(\mathrm{cm})$, and paw intensity (arbitrary units, 0-255).

\section{Statistical analysis}

For quantification, the value of the left contralateral side was normalized to $100 \%$. All statistical analyses were performed using GraphPad Prism v6.01. A D'AgostinoPearson omnibus normality test was performed. For cell survival, an unpaired $t$ test was used. For NPC differentiation, a 1-way ANOVA/Kruskal-Wallis test was used. For electrophysiology, a 1-way ANOVA was used. For all other outcome measures we used a 2-way ANOVA followed by a Bonferroni post hoc test. $F$ values, exact $t$ values, and when available, exact $p$ values are reported.
Values reported are mean \pm SD. n.s. = not significant; $* p<0.05 ; * * p<0.01 ; * * * p<0.001$.

\section{Results}

Our model of mild $\mathrm{HI}$ injury produced consistent structural changes in key brain regions and deficiencies in functional outcomes. NPC transplantation of exogenous NPCs into $\mathrm{HI}$ mice resulted in restoration of brain structures and motor performance.

Transplanted NPCs survive, migrate, differentiate morphologically, and integrate in the corpus

\section{callosum}

NPCs transplanted at PND21 into the injured CC (Fig. $2 A$ ) survived for up to 19 weeks (Fig. 2B-I). After 9 weeks, the survival rate between $\mathrm{HI}(4.25 \pm 0.79 \%)$ and sham $(4.53 \pm 0.53 \%)$ animals was similar (unpaired $t$ test, $p=$ 0.6586; Fig. 2J). Transplanted NPCs migrated through the $\mathrm{CC}$, colonized the injury site, and engrafted in the brain tissue, with an initial change in shape at day 4 (PND25) 
from a round-type cell (in vitro) to a fibroblast like cell (Fig. $2 B$ ). Afterward, the NPCs grew numerous processes into the neighboring brain structures and established a network (Fig. $2 \mathrm{C}-l$ ), suggesting some level of communication with neighboring brain structures such as the hippocampus, cortex, and internal capsule. Similar observations were made in the sham (data not shown).

Cultured NPCs $\left(\mathrm{YFP}^{+}\right)$grown in vitro stained positive for Nestin before transplantation (Fig. 3A). At 9 weeks posttransplantation, the vast majority of NPCs located within the lesioned CC expressed Nestin $(94.99 \pm 4.64 \%$; Kruskal-Wallis test; $p=0.8980$; Figs. $3 B$ and $2 G$ ), with very few NPCs differentiating into astrocytes $\left(\mathrm{GFAP}^{+}\right.$, $0.62 \pm 0.52 \%$, Kruskal-Wallis test; $p<0.0001$; Figs. $3 C$ and $2 G$ ), immature neurons $\left(\mathrm{DCX}^{+}, 0.90 \pm 0.57 \%\right.$, Kruskal-Wallis test; $p<0.0001$; Figs. $3 D$ and $2 G$ ), neurons $\left(\mathrm{NeuN}^{+}, 0.46 \pm 0.55 \%\right.$, Kruskal-Wallis test; $p<$ 0.0001 ; Figs. $3 E$ and $2 G$ ), or oligodendrocytes (Olig2 ${ }^{+}$, $1.43 \pm 0.77 \%$, Kruskal-Wallis test; $p=0.0002$; Figs. $3 F$ and $2 G$ ). When transplanted in the sham, the differentiation profile of NPCs was comparable. At 19 weeks posttransplantation, the proportion of cells differentiated into different cell types did not change compared to week 9 (data not shown).

\section{Transplanted NPCs lead to structural recovery at 9 weeks posttransplantation}

Our model of $\mathrm{HI}$ injury affects the brain structure, and NPC transplantation produces a substantial level of recovery. Representative pictures of brain coronal sections at three bregma levels show that the neonatal unilateral $\mathrm{HI}$ lesion occurs in the right ipsilateral brain hemisphere. Various structures such as the CC, the cortex, the hippocampus, the lateral ventricle, or the caudoputamen are affected (Fig. 4, middle column, arrows) compared to the sham control (Fig. 4, left column). Recovery is observed after NPCs are transplanted in the CC (Fig. 4, right column).

HI injury reduces the overall brain size, but NPC transplantation does not restore it

After $\mathrm{HI}$ injury, the brain size was affected, with the right injured hemisphere being significantly smaller (89.06 \pm $4.50 \%$, 2-way ANOVA, followed by Bonferroni's test, $F(2$, $208)=52.21$ ) compared to both the uninjured contralateral hemisphere (normalized at 100, $p<0.0001, t=$ 11.70) and the ipsilateral hemisphere of the sham animals (99.84 $\pm 5.13 \%, p<0.0001, t=13.03$; Fig. $5 A)$. After NPCs were transplanted in the CC of the $\mathrm{HI}$ injured animals, the size of the smaller right brain hemisphere persisted (89.70 $\pm 4.57 \%, p>0.9999, t=0.8597$; Fig. $5 A)$. The transplanted NPCs do not have a clear impact on the overall brain size reduction.

$H I$ injury significantly affects the hippocampus, and NPC transplantation leads to limited recovery

In $\mathrm{HI}$ injured animals, the right hippocampus was dramatically smaller $(19.73 \pm 21.63 \%, 2$-way ANOVA, followed by Bonferroni's test, $F(2,46)=41.08$ ) compared to the uninjured contralateral hemisphere (normalized at $100, p<0.0001, t=12.28$ ) or the ipsilateral hemisphere of the sham mice $(91.35 \pm 4.51 \%, p<0.0001, t=12.00$;
Fig. 5B). After NPC transplantation in the CC, the right hippocampus size increased notably (61.49 $\pm 6.68 \%)$, although the size remained smaller compared to the $\mathrm{HI}$ contralateral hippocampus (normalized at 100, $p<$ $0.0001, t=7.98$ ) and to the sham ipsilateral hippocampus $(91.35 \pm 4.51 \%, p<0.0001, t=5.87$; Fig. $5 B)$.

The neuronal population was also reduced following $\mathrm{HI}$ injury, with the number of $\mathrm{NeuN}^{+}$cells being dramatically smaller in the ipsilateral CA1 region of animals having received the vehicle $(69.41 \pm 13.99 \%$, ANOVA, followed by Bonferroni's test, $F(2,56)=24.75)$ compared to the uninjured contralateral CA1 (normalized at 100, $p<$ $0.0001, t=8.93)$ or to the ipsilateral CA1 of the control animals $(102.94 \pm 11.20 \%, p<0.0001, t=9.78$; Fig. $5 C)$. After NPC transplantation, the recovery of the neuron population of the ipsilateral CA1 was limited (84.62 \pm $10.97 \%$ ) compared to the ipsilateral side of the $\mathrm{HI}+$ vehicle group $(69.41 \pm 13.99 \%, p<0.0005, t=4.54$; Fig. $5 C)$.

Similarly, the number of $\mathrm{NeuN}^{+}$cells in the ipsilateral CA3 region was lower $(63.65 \pm 6.90 \%, 2$-way ANOVA, followed by Bonferroni's test, $F(2,56)=16.92)$ compared to the uninjured contralateral CA3 (normalized at 100, $p<$ $0.0001, t=8.07)$ or to the ipsilateral CA3 of the control animals $(99.33 \pm 7.93 \%, p<0.0001, t=7.92$; Fig. $5 D)$. The recovery was not significant following NPC transplantation $(74.92 \pm 13.58 \%)$ compared to the $\mathrm{HI}+$ vehicle group $(63.65 \pm 6.90 \%, p=0.1970, t=2.56$; Fig. $5 D)$. The transplanted NPCs led to a substantial, although not full, recovery of the hippocampus.

HI injury significantly affects the cortex, and NPC transplantation produces significant recovery

The ipsilateral somatosensory cortex (SSC) was thinner (86.83 $\pm 10.45 \%$, 2-way ANOVA, followed by Bonferroni's test, $F(2,38)=1.77)$ compared to the contralateral side (normalized at $100, p=0.02, t=3.44$ ) or to the ipsilateral side of sham animals $(102.04 \pm 4.48 \%, p=$ $0.25, t=2.51$; Fig. 5E). After NPC transplantation, the thickness of the SSC was restored (93.91 $\pm 8.47 \%$ ) compared to the contralateral side (normalized at 100, $p>$ $0.9999, t=1.22$ ) or the ipsilateral side of sham animals (102.04 $\pm 4.48 \%, p>0.9999, t=1.26$; Fig. $5 E$ ).

A significant decrease in the neuronal population was observed after $\mathrm{HI}$ injury in ipsilateral SSC $(87.75 \pm 6.18 \%$, 2-way ANOVA, followed by Bonferroni's test, $F(2,68)=$ 3.74 ) compared to the contralateral control side (normalized at $100, p=0.0005, t=4.46$ ) or the ipsilateral side of sham animals $(98.88 \pm 7.22 \%, p=0.0111, t=3.54$; Fig. $5 F$ ). After NPC treatment, the neuron population was restored in the SSC $(95.34 \pm 7.51 \%)$ compared with the contralateral side (normalized at 100, $p=0.9636, t=$ $1.88)$ and the ipsilateral side of the sham (98.88 $\pm 7.22 \%$, $p>0.9999, t=1.17$; Fig. 5F).

Similarly, the ipsilateral primary motor cortex (PMC) was thinner (89.97 $\pm 7.46 \%$, 2-way ANOVA, followed by Bonferroni's test, $F(2,38)=2.23$ ) compared to the contralateral side (normalized at 100, $p=0.0062, t=3.87$ ) or to the ipsilateral side of sham animals $(101.46 \pm 4.91 \%, p$ $=0.12, t=2.81$; Fig. 5G). After NPC transplantation, the thickness of the PMC was restored $(94.49 \pm 4.17 \%)$ 


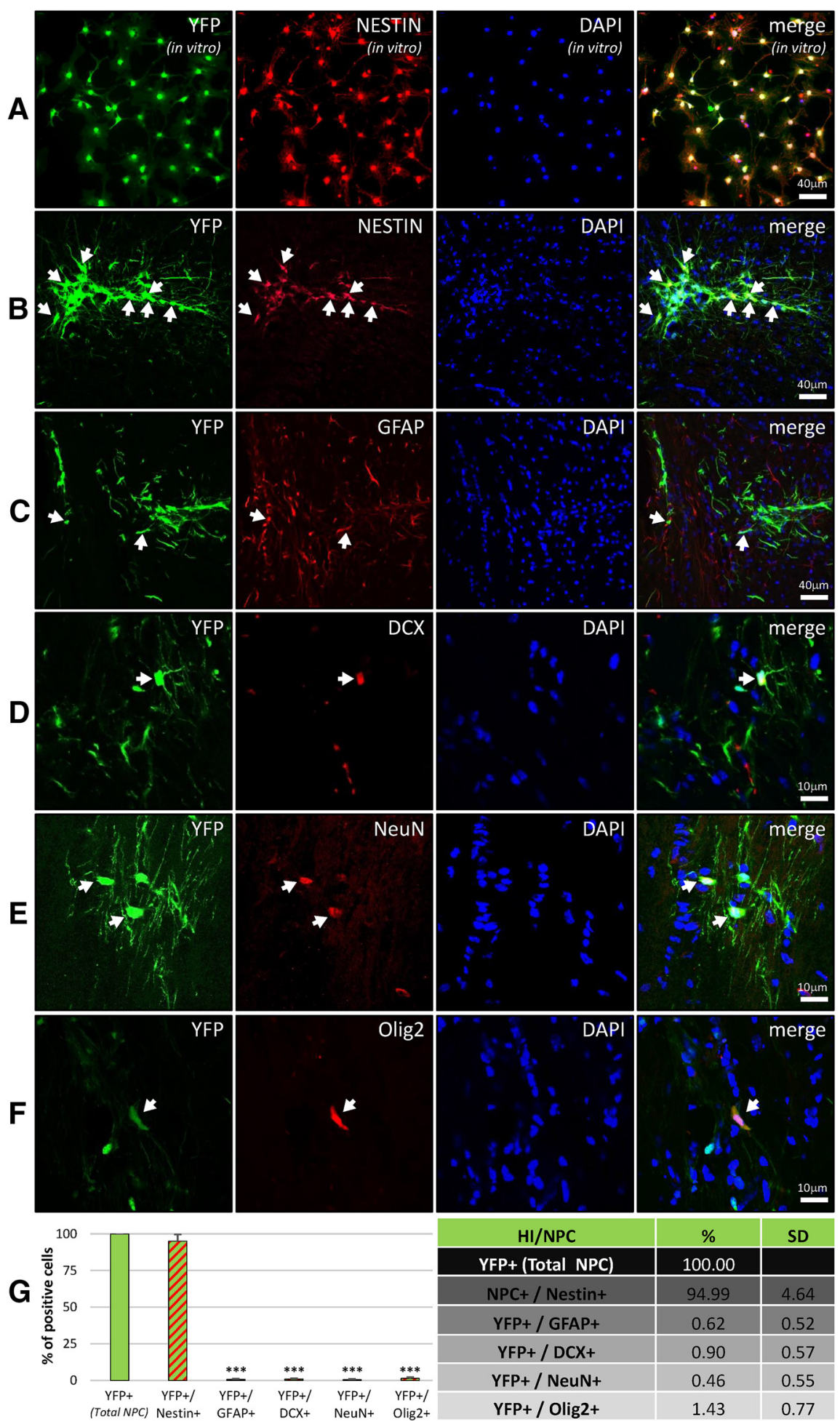

Figure 3. Some transplanted NPCs differentiate in the corpus callosum. $\boldsymbol{A}$, In vitro, all NPCs $\left(\mathrm{YFP}^{+}\right)$were also Nestin ${ }^{+}$. $\boldsymbol{B}-\boldsymbol{F}$, Nine weeks after transplantation, the majority of transplanted NPCs $\left(\mathrm{YFP}^{+}\right)$were also Nestin ${ }^{+}(\boldsymbol{B})$, while a few transplanted NPCs converted into different cell types: astrocytes $\left(\mathrm{GFAP}^{+}, \boldsymbol{C}\right)$, immature neurons $\left(\mathrm{DCX}^{+}, \boldsymbol{D}\right)$, neurons $\left(\mathrm{NeuN}^{+}, \boldsymbol{E}\right)$ or oligodendrocytes $\left(\mathrm{Olig} 2^{+}, \boldsymbol{F}\right)$. The vast majority of transplanted $\mathrm{NPCs}$ $(>94 \%)$ were negative for GFAP, DCX, NeuN, or Olig2. G, After transplantation in sham or HI mice, $<1 \%$ of NPCs differentiated to GFAP ${ }^{+}$, DCX ${ }^{+}$ or $\mathrm{NeuN}^{+}$cells, and $<2 \%$ differentiated to Olig2 ${ }^{+}$cells, while $>94 \%$ were $\mathrm{Nestin}^{+}$. $* * * p<0.001$.

compared to the contralateral side (normalized at 100 , $p>0.9999, t=1.63)$ or the ipsilateral side of sham animals (101.46 $\pm 4.91 \%, p>0.9999, t=1.59$; Fig. $5 G)$.
A significant decrease in the neuronal population was observed after $\mathrm{HI}$ injury in ipsilateral PMC (90.11 \pm $4.12 \%, 2$-way ANOVA, followed by Bonferroni's test, $F(2$, 


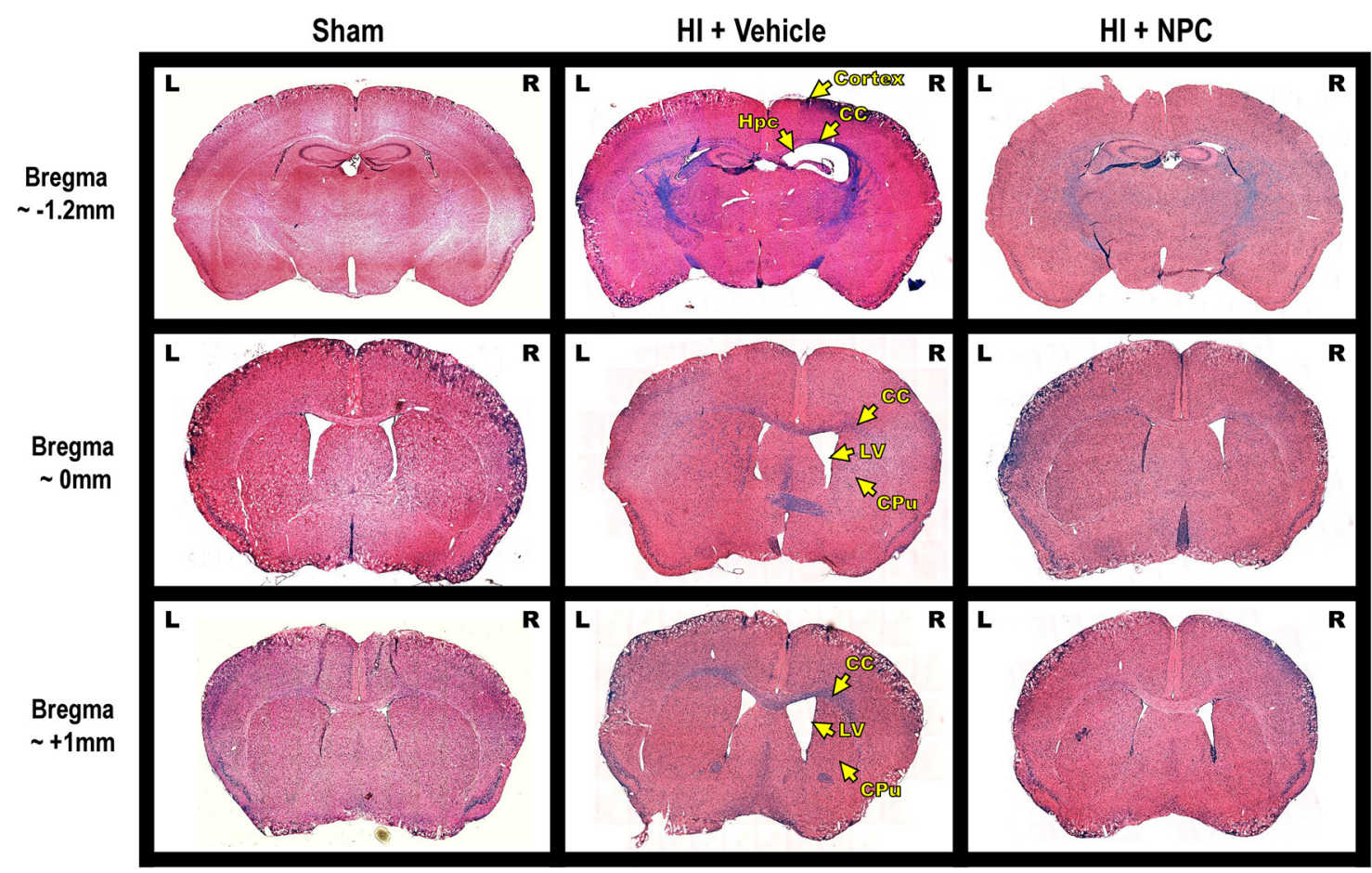

Figure 4. A unilateral injury is generated in different brain structures which, to various extents, are recovered after NPC transplantation. Representative pictures of LFB/H\&E brain coronal sections of sham (left column), HI + vehicle (middle column) and HI $+\mathrm{NPCs}$ (right column) at 3 different bregma levels that encompass the injury site [ $-1.2 \mathrm{~mm}$ (first line), $0 \mathrm{~mm}$ (second line), and $+1 \mathrm{~mm}$ (third line)]. After neonatal $\mathrm{HI}$, brain lesions were observed in several structures of the right ipsilateral hemisphere, such as the corpus callosum (CC), the cortex, the hippocampus (Hpc), the lateral ventricle (LV), or the caudoputamen (CPu). Various levels of recovery were observed after NPC transplantation in the CC.

$68)=8.85$; Fig. $5 H)$ compared to the contralateral control side (normalized at $100, p<0.0001, t=5.99$ ) or the ipsilateral side of sham animals $(99.57 \pm 2.59 \%, p<$ $0.0001, t=5.00$; Fig. 5H). After NPC treatment, the neuron population was restored in the PMC $(98.81 \pm$ 4.84\%) compared with the contralateral side (normalized at $100, p>0.9999, t=0.80$ ) and the ipsilateral side of the sham $(99.57 \pm 2.59 \%, p>0.9999, t=0.42$; Fig. $5 H)$.

The decreased neuron population in the cortex is shown in representative pictures taken in the SSC: $\mathrm{NeuN}^{+}$ neurons in the left/control side of an $\mathrm{HI}$ brain (Fig. 5/), the right side of the sham brain (Fig. 5J), the right/injured side of the $\mathrm{HI}$ brain (Fig. $5 K$ ) and the right/injured side of the $\mathrm{HI}$ brain treated with NPCs (Fig. $5 L$ ). The transplanted NPCs generate a significant recovery of the cortex structure and neuronal population.

\section{$\mathrm{HI}$ injury significantly affects the corpus callosum, and transplanted NPCs lead to recovery}

The areas assessed on anterior and posterior coronal sections (Fig. 5M) show a significant decrease of the right injured CC area $(75.04 \pm 4.48 \%$, 2-way ANOVA, followed by Bonferroni's test, $F(2,154)=117.0)$ compared to the uninjured contralateral CC (normalized at 100, $p<$ $0.0001, t=17.37$ ) or to the ipsilateral CC of the control animals (98.08 $\pm 3.67 \%, p<0.0001, t=17.37)$. After NPC transplantation in the CC, the area of the right CC $(95.58 \pm 5.88 \%)$ was markedly restored compared to the vehicle group $(75.04 \pm 4.48 \%, p<0.0001, t=17.73)$ and became similar to control values (contralateral normalized at 100: $p<0.05, t=5.44$; and ipsilateral sham: $97.21 \pm$ $4.62 \%, p>0.9999, t=1.68$ ).

Similarly, the volumetric assessment of the CC (Fig. $5 N$ ) at the level of the transplantation site, from bregma -1.5 to $+1.5 \mathrm{~mm}$, showed a volume decrease of the right injured CC $(63.93 \pm 2.21 \%$, 2-way ANOVA, followed by Bonferroni's test, $F(2,34)=228.6)$ compared to the uninjured contralateral CC (normalized at 100, $p<0.0001, t=$ $24.18)$ or to the ipsilateral $C C$ of the sham animals (104.08 $\pm 2.21 \% p<0.0001, t=27.40)$. After NPC transplantation in the CC, the volume of the right CC (103.15 \pm $3.82 \%)$ was significantly improved compared to the vehicle group $(63.93 \pm 2.21 \%, p<0.0001, t=27.40)$ and became similar to control values (contralateral normalized at 100: $p=0.8822, t=1.96$; and ipsilateral sham: 104.80 $\pm 2.21 \%, p>0.9999, t=1.06)$. The corpus callosum is fully recovered after NPC transplantation.

\section{HI injury trigger glial scar formation, and transplanted NPCs partially reduce gliosis in the CC}

The $\mathrm{HI}$ injury triggered gliosis in the injured hemisphere, which was observed mainly in the CC, the sensorimotor cortex, the hippocampus, and the internal capsule (Fig. $6 A)$. Representative pictures at higher magnification show that the $\mathrm{GFAP}^{+}$cell population, as well as the production of the glial scar component chondroitin sulfate proteoglycan (CSPG - CS6), were increased in the CC after HI. Importantly, following NPC treatment we observed a decrease in gliosis (Fig. 6B). 
A Brain Hemisphere Area (\%)

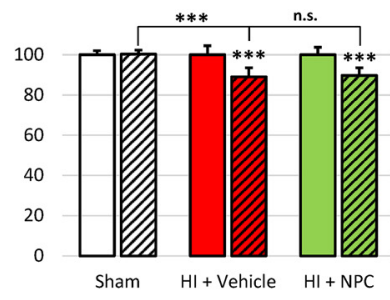

C Neuron counts in CA1 (\%)

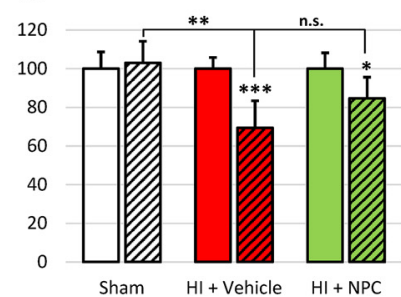

\section{E}

Somatosensory Cortex Thickness (\%)

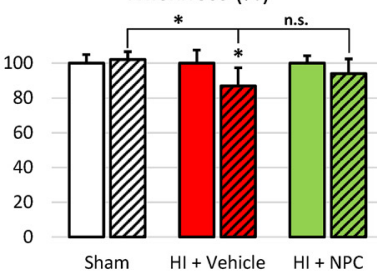

G Primary Motor Cortex Thickness (\%)
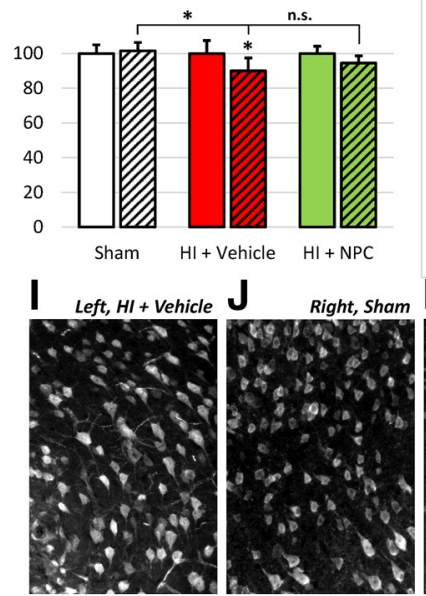

M Corpus Callosum Area (\%)

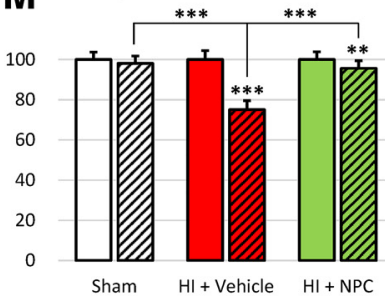

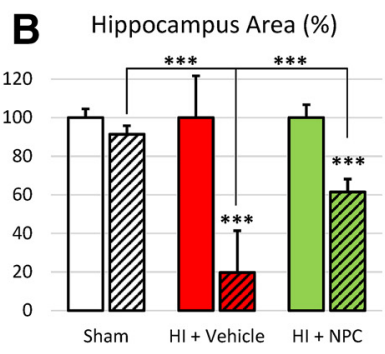

D Neuron counts in CA3 (\%)

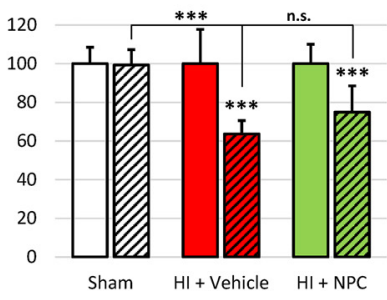

F Somatosensory Cortex (\%)

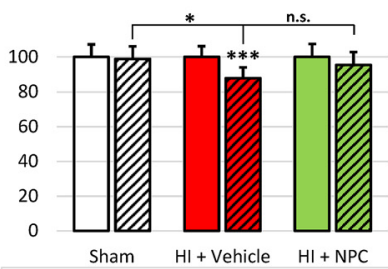

H

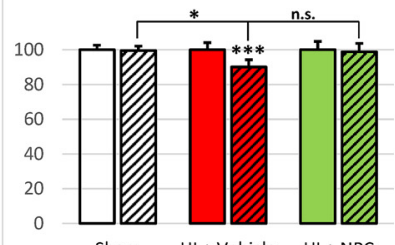

K

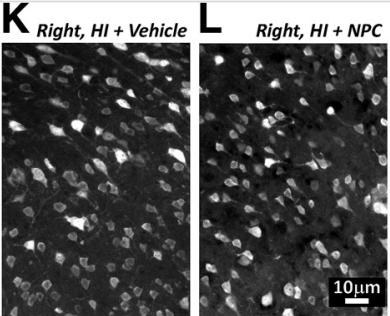

$\mathrm{N}$

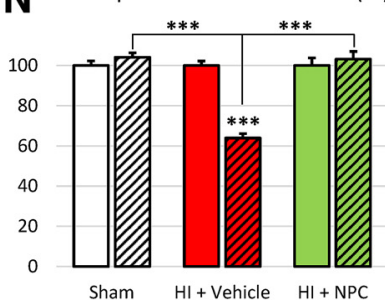

Figure 5. Transplanted NPCs restore the integrity of various structures of the brain, including the corpus callosum. Various brain structures were affected by the $\mathrm{HI}$ injury. $\boldsymbol{A}$, The size of the right brain hemisphere was decreased after $\mathrm{HI}$ injury, which was not significantly corrected after NPC transplantation. $\boldsymbol{B}$, The hippocampus was also affected by the $\mathrm{HI}$ injury, and NPC transplantation had only a limited impact on recovery. $\boldsymbol{C}, \boldsymbol{D}$, After $\mathrm{HI}$

Figure 5. continued

injury, the neuron population was also decreased in the CA1 (C) and CA3 $(\boldsymbol{D})$ regions, and the NPCs had a limited effect on recovery. $\boldsymbol{E}, \boldsymbol{F}$, The thickness of the somatosensory cortex (SSC; $\boldsymbol{E})$ and the primary motor cortex (PMC; $\boldsymbol{F}$ ) were decreased after $\mathrm{HI}$ injury; the NPCs had a limited effect on recovery. $\boldsymbol{G}, \boldsymbol{H}$, The $\mathrm{NeuN}^{+}$neuron population was decreased in the SSC (G) and in the PMC $(\boldsymbol{H})$ after $\mathrm{HI}$ injury, and the NPCs had a limited effect on recovery. $\boldsymbol{I}-\boldsymbol{L}$, Representative pictures of $\mathrm{NeuN}^{+}$neurons in the SSC of the left/control side of a $\mathrm{HI}$ brain (I), the right side of the sham brain $(\boldsymbol{J})$, the right/injured side of the $\mathrm{HI}$ brain $(\boldsymbol{K})$, and the right/injured side of the HI brain treated with NPCs $(\boldsymbol{L})$. $\boldsymbol{M}$, The HI injury also led to the decrease of the CC area assessed on coronal sections. $\boldsymbol{N}$, Stereological analysis confirmed the impact on the CC with a volume decrease. After NPC transplantation, recovery was observed. The left side has been normalized to $100 \%$ and is compared with the right side. The dashed versus plain bars represent the right versus left side, respectively. $* p<$ $0.05, * * p<0.01, * * * p<0.001$

$H \mathrm{H}$ injury significantly affects the lateral ventricle, and transplanted NPCs lead to substantial recovery

$\mathrm{MRI}$ analysis demonstrated clear unilateral damage to the right brain hemisphere following $\mathrm{HI}$ injury, with the right lateral ventricle (LV) being significantly enlarged compared to the control (Fig. 7A, arrows). Volumetric measurements (2-way ANOVA, followed by Bonferroni's test, $F(2,36)=15.55)$ showed that the right $L V$ was dramatically enlarged $(71.27 \pm 12.34 \%$ of the total LV volume, i.e., right LV + left LV), compared to the contralateral LV (28.73 $\pm 12.34 \%, p<0.0001, t=8.36)$ and to the ipsilateral LV of sham animal (51.33 $\pm 4.83 \%, p=0.058$, $t=3.92)$. After NPC transplantation in the CC, the right ventricle size became smaller $(59.27 \pm 9.83 \%)$ than pretransplantation, although it remained larger than controls compared to the contralateral LV $(40.73 \pm 9.83 \%, p=$ $0.0127, t=3.64)$ and to the ipsilateral LV of sham animal $(51.33 \pm 4.83, p>0.9999, t=1.56)$. The transplanted NPCs trigger a significant recovery of the ventricle volume (Fig. 7B).

\section{Transplanted NPCs lead to myelination}

HI injury significantly decreased the OL population, whereas transplantation of exogenous NPCs increased the endogenous OL population, including mature OLs

The endogenous OL (Olig2 ${ }^{+}$) population (Fig. 8A) was significantly decreased after $\mathrm{HI}$ insult in the injured right CC (57.85 $\pm 2.19 \%$, 2-way ANOVA, followed by Bonferroni's test, $F(2,34)=184.1)$ compared to the uninjured contralateral CC (normalized at 100, $p<0.0001, t=$ 14.37) or the ipsilateral CC of the sham animals (102.96 \pm $2.54 \%, p<0.0001, t=15.38)$. After NPC transplantation, the Olig ${ }^{+}$cell population was markedly increased above the control level in the injured right CC (139.50 $\pm 9.43 \%$, $p<0.0001, t=12.47)$. Interestingly, the vast majority of those Olig2 ${ }^{+}$cells were also negative for the YFP-tag applied to NPCs.

The mature $\mathrm{OL}$ population $\left(\mathrm{CC}^{+} / \mathrm{Olig} 2^{+}\right.$; Fig. 8B,C) was also affected by $\mathrm{HI}$ injury (2-way ANOVA, followed by Bonferroni's test, $F(2,64)=7.94)$. A decrease was observed $(69.32 \pm 6.74 \%)$ compared to the uninjured con- 
A

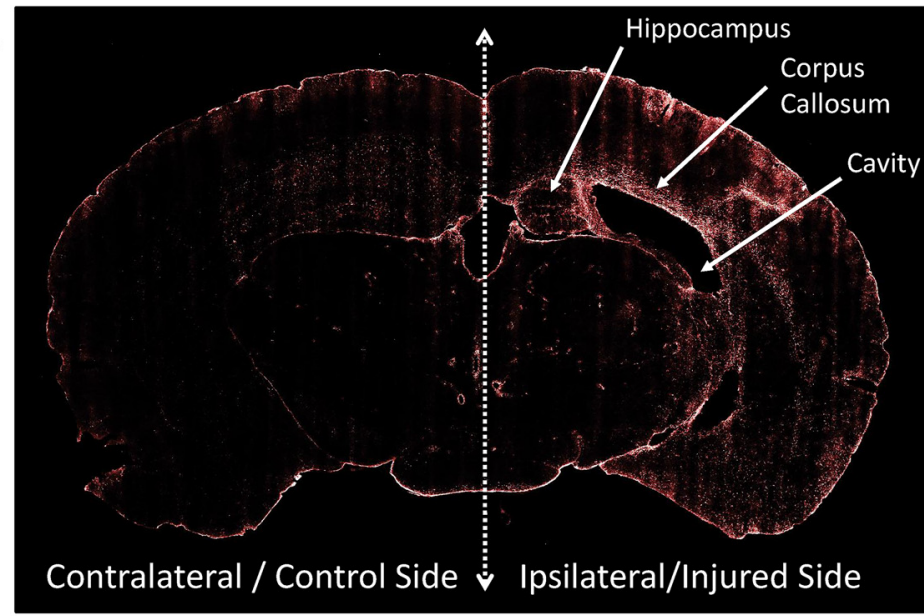

B
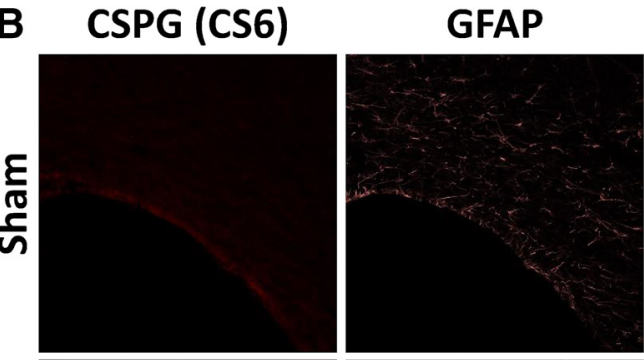

Merge
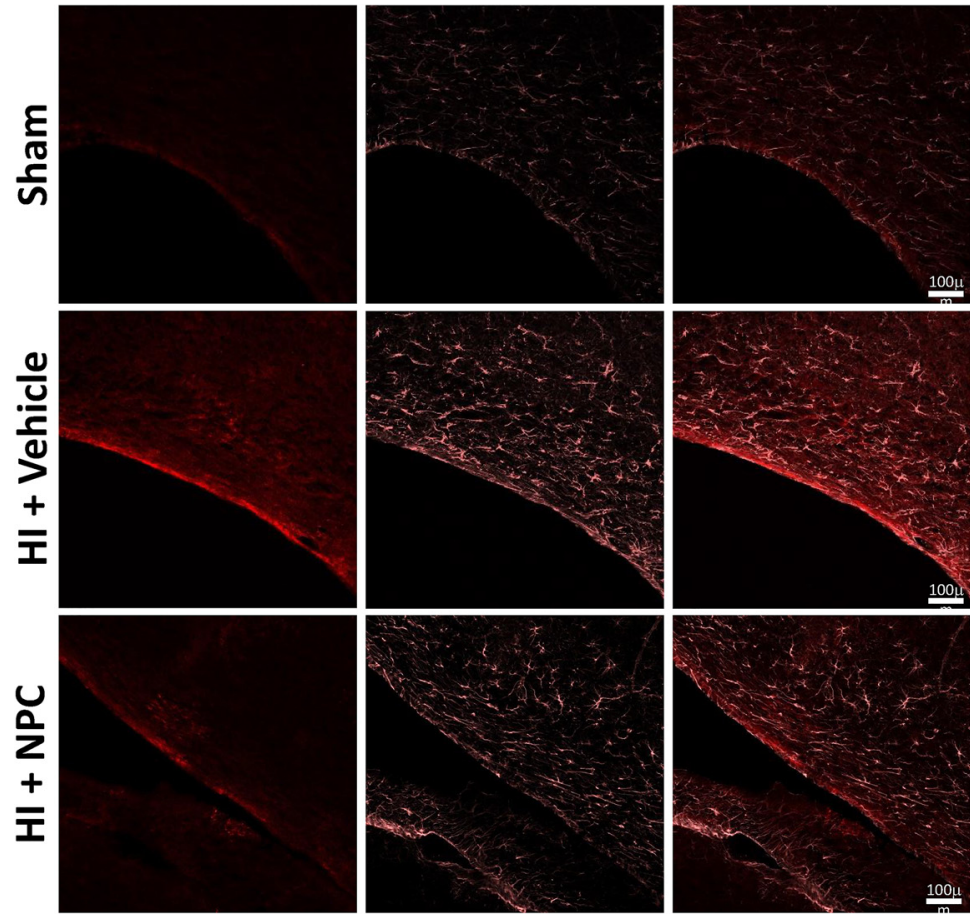

Figure 6. Transplanted NPCs do not significantly reduce glial scar formation. $\boldsymbol{A}$, Representative picture of a coronal brain section showing the left uninjured control side and the right $\mathrm{HI}$ injured side: GFAP staining is increased in several regions including the CC, the sensorimotor cortex, or the hippocampus. B, Representative pictures of the CC at high magnification from control, $\mathrm{HI}+\mathrm{Vehicle}$ and $\mathrm{HI}+$ NPC mice: the increased GFAP and CSPG staining levels show gliosis after HI injury, while a certain level of recovery is observed after NPC treatment.

tralateral CC (normalized at 100, $p=0.0001, t=4.88$ ) and the ipsilateral CC of the control animals $(97.20 \pm 21.39 \%$, $p=0004, t=4.56)$. In $\mathrm{HI}+\mathrm{NPC}$ animals, the mature OL population $(97.05 \pm 12.98 \%)$ was restored to uninjured levels and became similar to control values (contralateral normalized at 100: $p>0.9999, t=0.63$; and ipsilateral sham: $97.20 \pm 21.391 \%, p>0.9999, t=0.03$ ).

Fig. $8 \mathrm{C}$ shows representative images of Olig2 ${ }^{+} / \mathrm{CC}^{-}$ cells (immature OLs), Olig2 ${ }^{-} / \mathrm{CC}^{+}{ }^{+}$(astrocytes) and Olig2 ${ }^{+} / \mathrm{CC}{ }^{+}$(mature OLs). The transplanted NPCs lead to a major increase of the mature and immature OL population in the CC.
$\mathrm{HI}$ injury significantly affects the myelination of the CC, and NPCs lead to functional myelination

Functional myelination of the $\mathrm{CC}$ was assessed by electrophysiology. After unilateral $\mathrm{HI}$ injury, the amplitude of peak1 (myelinated axons) was significantly reduced in the right/injured side of the CC $(0.27 \pm 0.04 \mathrm{mV}, n=15)$ compared to the left/uninjured control side $(0.53 \pm 0.03$ $\mathrm{mV}, n=25,1$-way ANOVA, $p<0.0001, t=-5.14, F=$ 13.38), while the amplitude of peak2 (non-myelinated axons) was not significantly decreased in $\mathrm{HI}$ injured animals (Fig. $9 C, D$ ). Additionally, the CV of peak1 was dramatically attenuated in the right/injured side of the CC $(0.84 \pm 0.01$ 
A
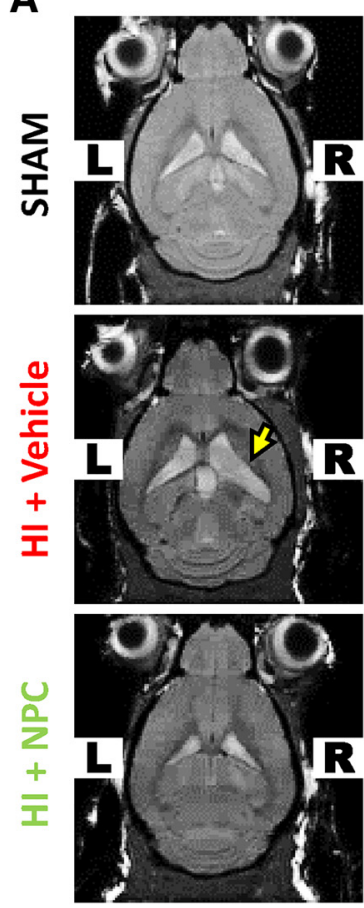
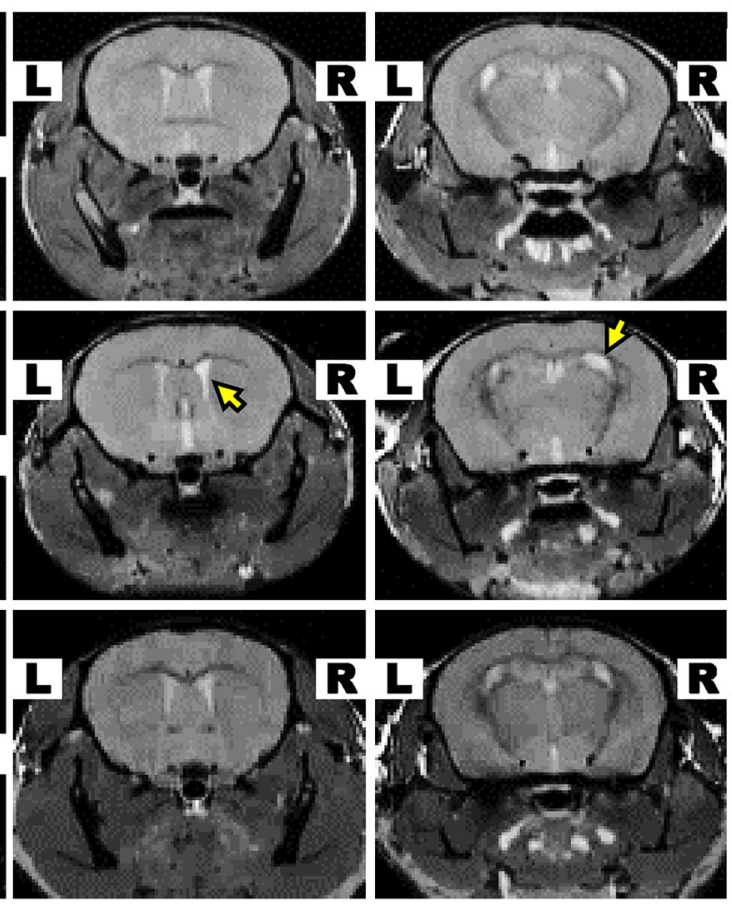

B
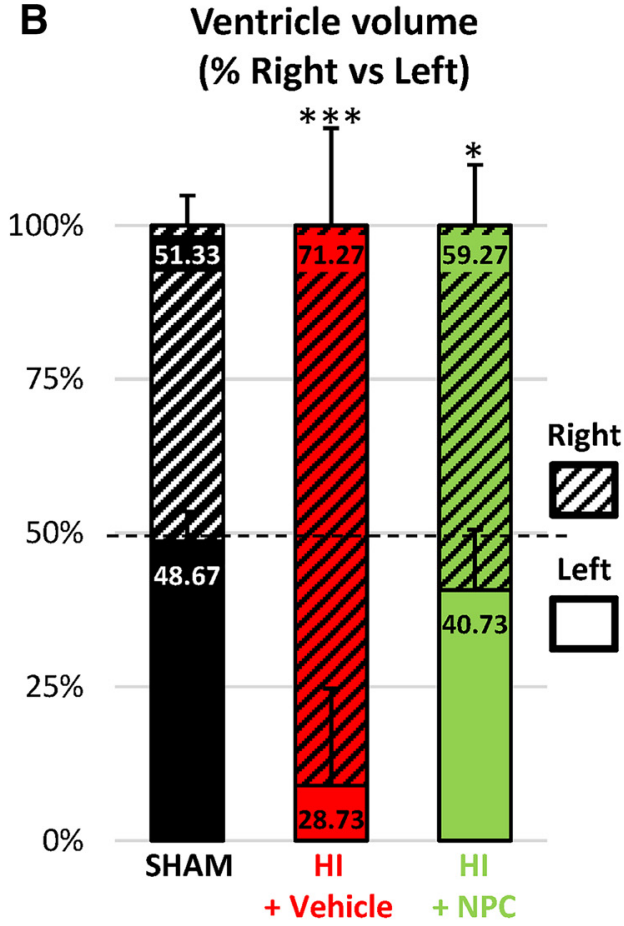

Figure 7. Transplanted NPCs help to recover the ventriculomegaly. $\boldsymbol{A}, \mathrm{MRI}$ shows right unilateral ventriculomegaly after HI injury (arrow) on axial sections (left column), coronal sections at the anterior brain level (middle column), and coronal sections at the posterior brain level (right column). B. The percentage of right (dashed) versus left (plain) lateral ventricle showed a significant enlargement after $\mathrm{HI}$ (in red) compared to sham (in black). After NPC transplantation (in green) the brain structures, including the ventricle size, were partially restored $(\boldsymbol{A}$ and $\boldsymbol{B}) . * p<0.05, * * p<0.01, * * * p<0.001$.

$\mathrm{m} / \mathrm{s}, n=15)$ compared to the left/control side of the CC $(0.94 \pm 0.01 \mathrm{~m} / \mathrm{s}, n=25, p<0.0001, t=-6.2113, F=$ 19.37), but not in peak2 after $\mathrm{HI}$ (Fig. 9C,D). These results suggest that myelinated axons in the CC were dramatically degenerated and remained unmyelinated after unilateral $\mathrm{HI}$ injury, while nonmyelinated axons were not significantly affected. This data are supported by the significantly elevated peak2/peak1 ratio amplitude in the right/injured side of the CC $(0.81 \pm 0.05, n=15) \mathrm{com}-$ pared to left/control side of the CC $(0.46 \pm 0.04, n=25$, $p<0.0001, t=5.79, F=18.67$; Fig. 9D). Fig. $9 E$ shows superimposed CAPs recorded at varying stimulus intensities $(0.01 \sim 1.5 \mathrm{~mA})$ from the left/control side, right/injured side of $\mathrm{HI}+$ vehicle mice and right/injured side of $\mathrm{HI}$ + NPC mice for the CC. Fig. 9F shows the relationship between stimulus intensity and CAP peak1 amplitude. Stronger stimulus intensities are required to generate CAPs in myelinated axons of the right/injured side of the CC compared to those of the left/control side of the CC (Fig. 9F, left plot). This suggests that larger myelinated axons are preferentially injured by $\mathrm{HI}$.

After NPCs transplantation in the right/injured CC, the peak1 amplitude was significantly elevated $(0.46 \pm 0.04$ $\mathrm{mV}$ ) and was not significantly different anymore from the control $(0.53 \pm 0.03 \mathrm{mV}, p=0.8382, t=-1.09$; Fig. $9 C, D)$. The CV of peak1 CAPs also increased following NPC transplantation $(0.91 \pm 0.02 \mathrm{~m} / \mathrm{s})$ and became comparable to the control $(0.84 \pm 0.01 \mathrm{~m} / \mathrm{s}, p=0.3135, t=-1.65$; Fig. $9 C, D$ ). The peak2/peak1 ratio amplitude was significantly reduced from $0.81 \pm 0.05(\mathrm{HI}+$ vehicle $)$ to $0.49 \pm$
$0.04(\mathrm{HI}+\mathrm{NPC}, p<0.0001, t=-4.5933)$ and was not significantly different anymore from the control $(0.46 \pm$ 0.04, $n=25, p>0.9999, \mathrm{t}=0.04$; Fig. 9D). There were no significant effects of transplanted NPCs on peak2 of CAPs. The deficiency observed in $\mathrm{HI}$ animals with respect to stimulus intensity and peak1 amplitude was recovered after NPCs transplantation (Fig. 9F, right plot). CAP data suggest that after unilateral $\mathrm{HI}$ injury, NPCs significantly protect the myelinated axons and myelinate the unmyelinated axons, especially axons with a larger diameter.

\section{Transplanted NPCs lead to functional recovery}

The cylinder test

In our unilateral HI injury model only the ipsilateral/right brain hemisphere is injured, thus injured mice are anticipated to preferentially use the right unaffected forelimb (Fig. 10A,B). Before NPC transplantation at PND20, HI mice showed a clear preference to use the right forelimb for support during rearing exploration sequences (65.47 \pm $0.77 \%$, 2-way ANOVA, followed by Bonferroni's test, $F(2$, $216)=190.8)$ compared to control mice (49.92 $\pm 1.21 \%$, $p<0.0001, t=4.93)$. Following NPC transplantation, the preference for using the right forelimb gradually disappeared, and after 9 weeks, there was no forelimb use asymmetry in $\mathrm{HI}+\mathrm{NPC}$ mice $(52.69 \pm 1.65 \%)$ compared to the control mice $(46.83 \pm 1.41 \%, p=0.0551, t=2.38$; Fig. 10A). Conversely, the preferential use of the right forelimb persisted in the untreated, $\mathrm{HI}+$ vehicle mice $(67.07 \pm 1.19 \%)$ compared to the control mice (46.83 \pm $1.41 \%, p<0.0001, t=6.42$; Fig. 10A). 


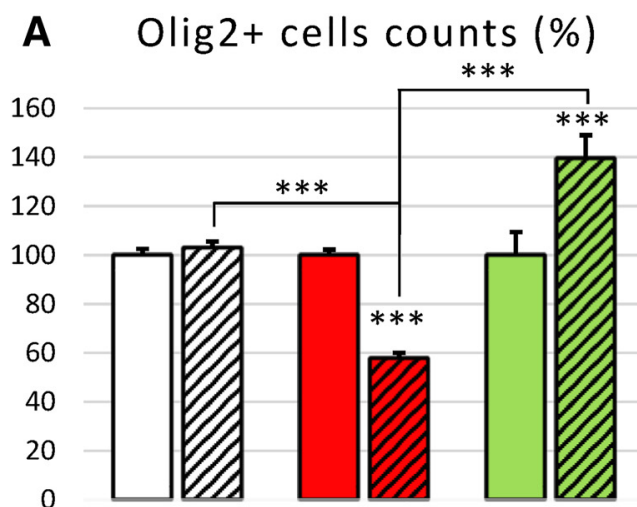

Sham

$\mathrm{HI}+$ Vehicle $\mathrm{HI}+\mathrm{NPC}$

B

Mature OL (\%)

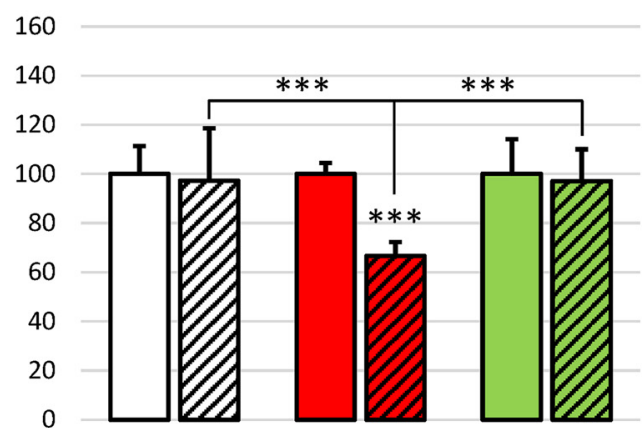

Sham

$\mathrm{HI}+$ Vehicle

$\mathrm{HI}+\mathrm{NPC}$

\section{C}
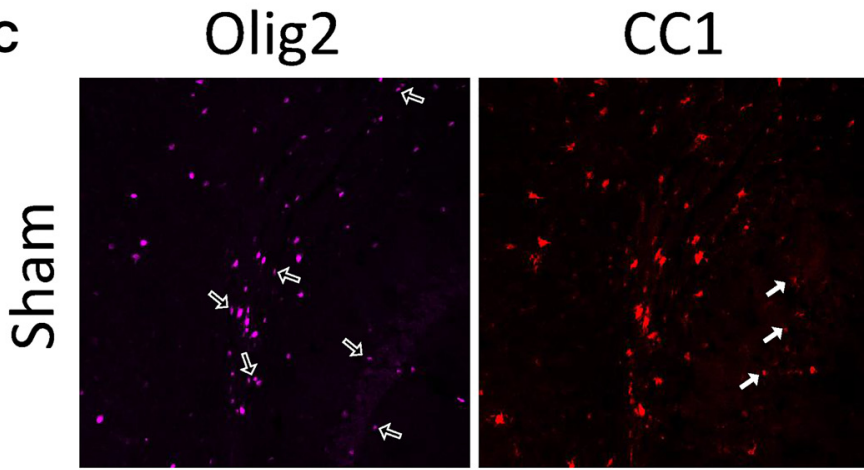

CC1

Merge
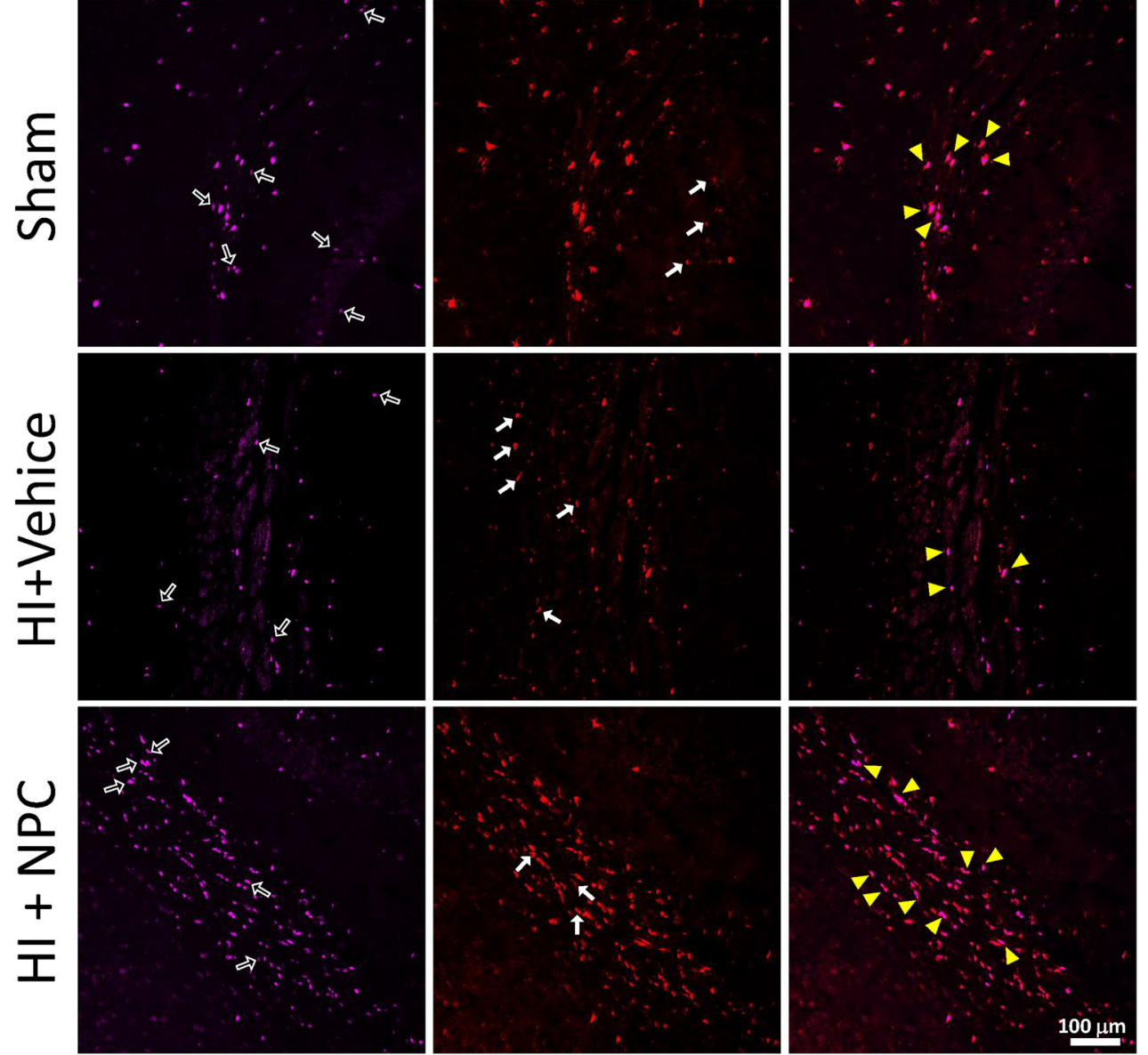

Figure 8. Transplanted NPCs have an impact on the endogenous oligodendrocyte population in the corpus callosum. Volumetric assessment of the oligodendrocyte population was performed around the sites of NPC transplantation (3-mm coronal virtual slice). $\boldsymbol{A}, \mathrm{A}$ significant decrease of Olig2 ${ }^{+}$cells was observed in the right $\mathrm{CC}$ after $\mathrm{HI}$ injury, while after transplantation, the Olig2 ${ }^{+}$cell population was dramatically increased. $\boldsymbol{B}$, The mature $\mathrm{OL}\left(\mathrm{Olig} 2^{+} / \mathrm{CC}^{+}\right)$population was also impacted after $\mathrm{HI}$ injury and was restored after NPC treatment. $\boldsymbol{C}$, Representative pictures of immature (Olig $2^{+} / \mathrm{CC} 1^{-}$; black arrows) and mature $\left(\mathrm{Olig} 2^{+} / \mathrm{CC} 1^{+}\right.$; yellow arrowheads) oligodendrocytes and astrocytes (Olig2 ${ }^{-} / \mathrm{CC}^{+}{ }^{+}$, white arrows). The dashed versus plain bars represent the right versus left side, respectively. $* p<0.05, * * p<0.01, * * * p<0.001$.

The choice of forelimb to start a rearing sequence also demonstrated functional asymmetry. Before NPC transplantation (PND20), the $\mathrm{HI}$ mice showed a clear preference for the right forelimb $(80.51 \pm 1.55 \%, 2$-way
ANOVA, followed by Bonferroni's test, $F(2,216)=336.1)$ compared to the control mice $(50.32 \pm 0.99 \%, p<$ $0.0001, t=6.74)$. Following NPC transplantation, the right forelimb preference was reduced in HI + NPC mice, and 
A

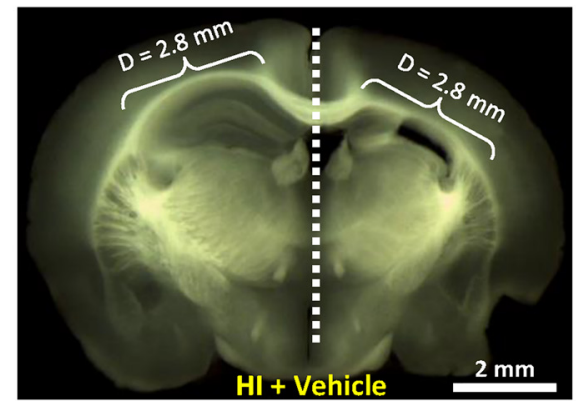

C

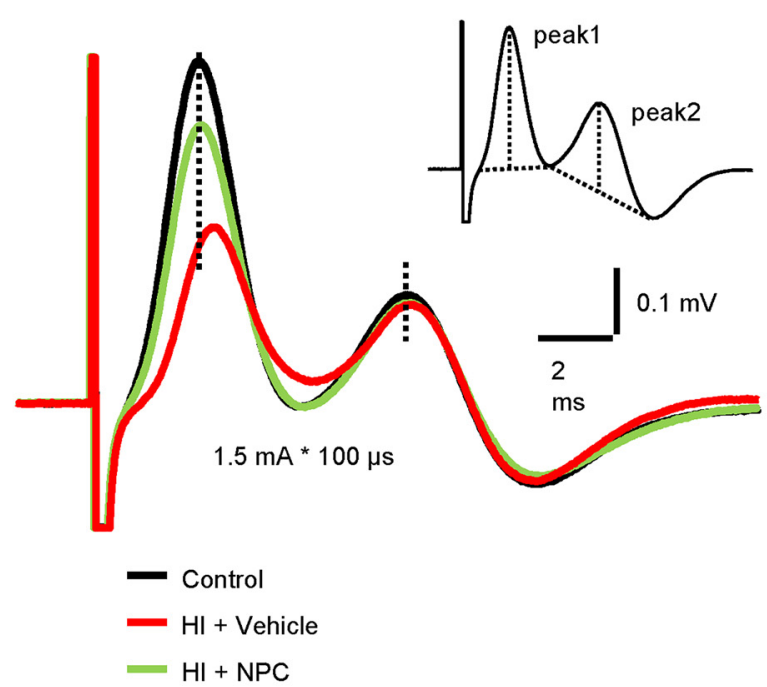

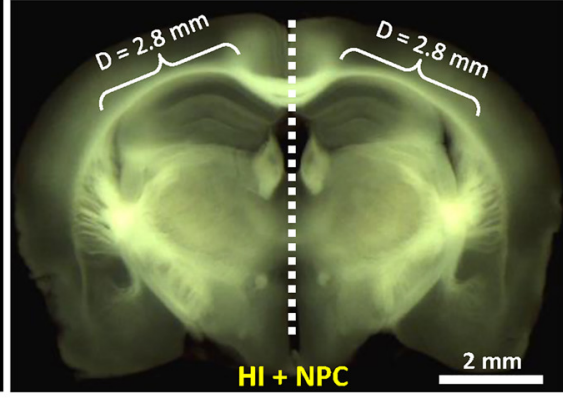

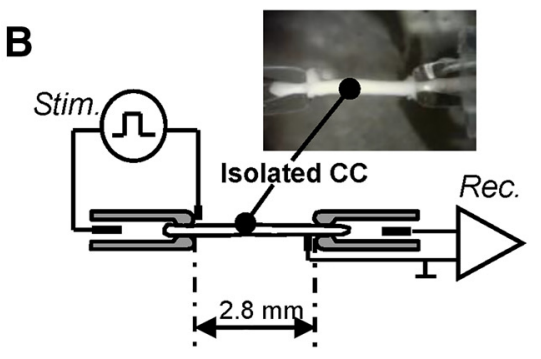

conduction distance

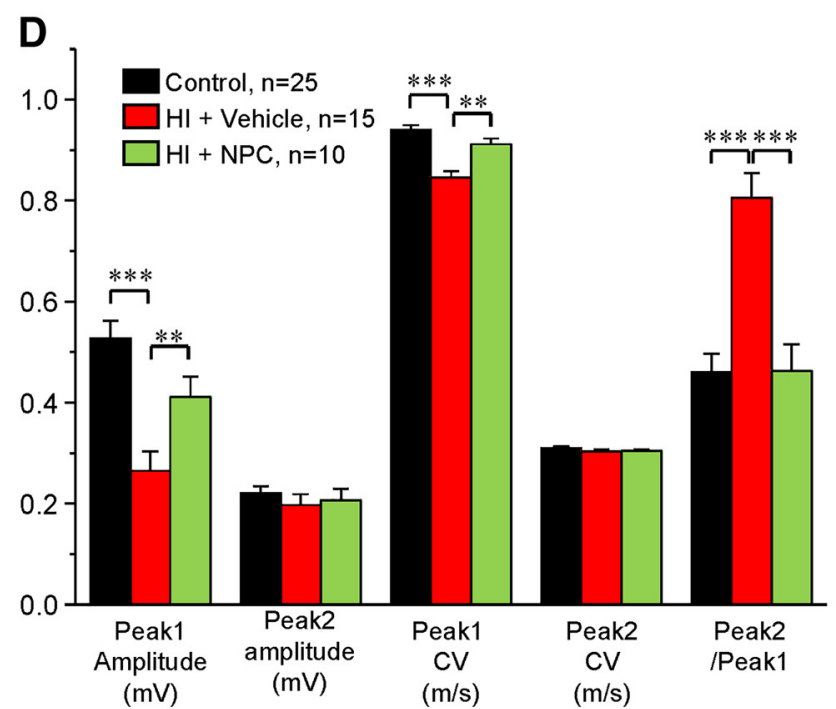

E

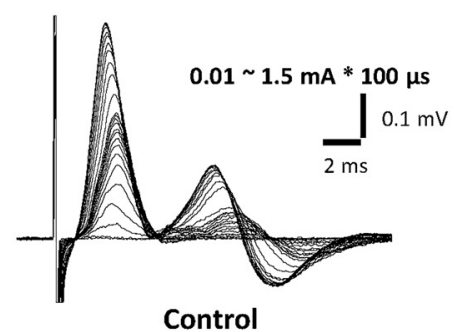

Control

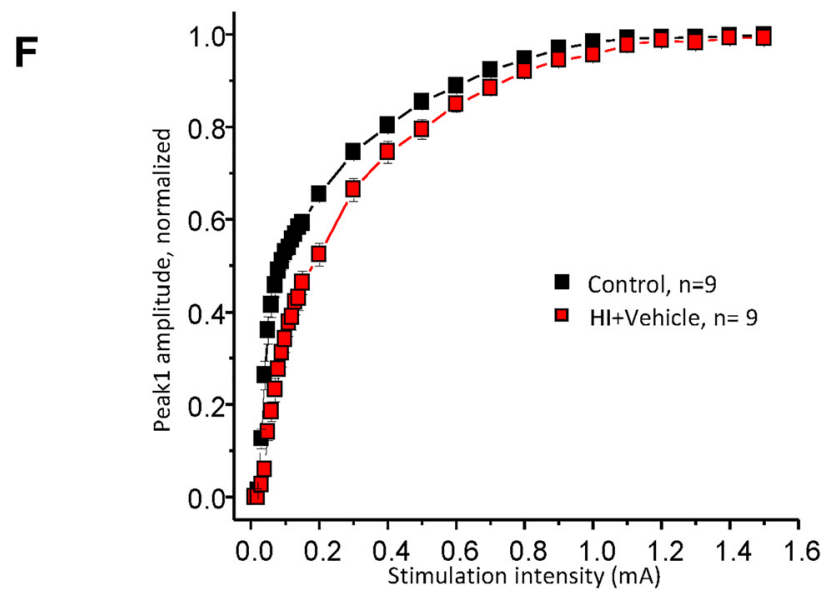

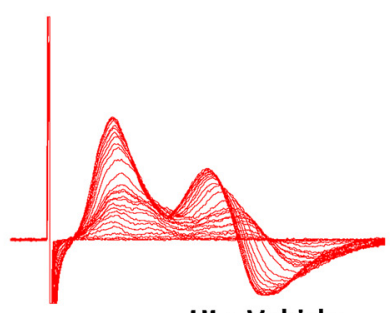

$\mathrm{HI}+$ Vehicle

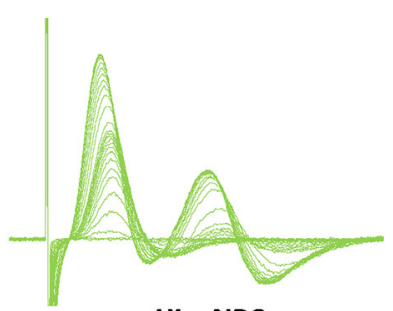

HI + NPC

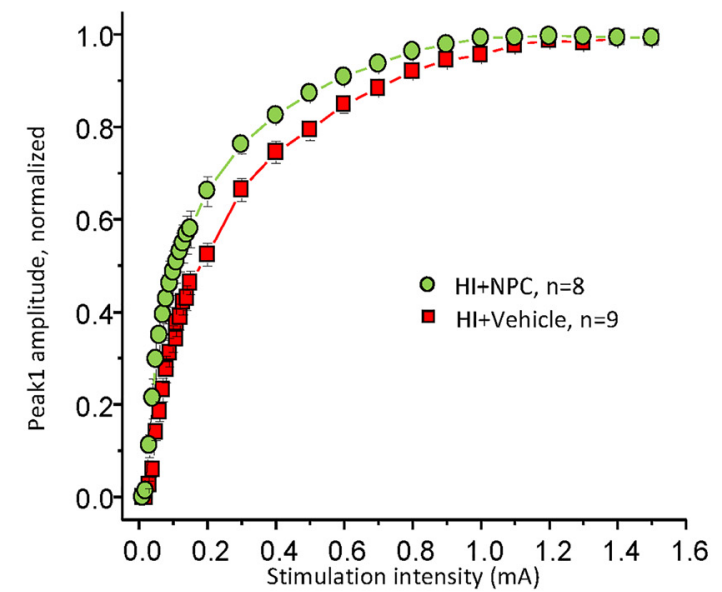

Figure 9. NPCs contribute to myelination after transplantation (electrophysiology). A, Electrophysiological properties of the CC from $\mathrm{HI}+$ Vehicle $(n=15)$ and HI + NPCs $(n=10)$ mice: coronal slices $(400 \mu \mathrm{m})$ of a HI (left side) and HI + NPCs (right side) from HI mice brains. $\boldsymbol{B}$, Diagram of the suction electrode recording method. The conduction distance of CC was 2.8 mm. $\boldsymbol{C}$, Averaged CAP traces recoded from left/control side of the CC $(n=15+10$, black line), right/injured side of the CC $(n=15$, red line) and right/injured side of the CC after NPC transplantation ( $n=10$, green line), respectively. Inset: the measurement of CAP amplitudes. $\boldsymbol{D}$, Detailed statistical comparison of CAP parameters from left/control CC (black bars), right/injured CC (red bars), and right/injured CC after 
continued

transplantation (green bars). Conduction velocity (CV) calculated through the recording distance (2.8 mm) divided by the time between artifact and peak. $\boldsymbol{E}$, Relationship between stimulus intensities and amplitudes of CAPs: representative superimposed CAPs recorded at varying stimulus intensities $(0.01 \sim 1.5 \mathrm{~mA})$ from left/control CC (left traces), right/injured CC (middle traces), and right/injured CC after NPC transplantation (right traces). $\boldsymbol{F}$, Comparison of the stimulus-response relationship of peak1 between left/control CC and right/injured CC (left plot, black and red, respectively); between right/injured CC with or without NPC treatment (right plot, red and green, respectively). All recordings were performed at room temperature. $* p<0.05, * * p<0.01, * * * p<0.001$.

after 9 weeks it was not significantly different compared to the control $(54.91 \pm 2.58 \%$ versus $49.75 \pm 1.56 \%, p=$ $0.4257, t=1.47$; Fig. 10B). In contrast, $\mathrm{HI}+$ vehicle mice continued to use the right forelimb more frequently $(87.31$ $\pm 1.90 \%)$ than the control mice $(87.31 \pm 1.90 \%$ versus $49.75 \pm 1.56 \%, p<0.0001, t=8.39$; Fig. 10B). The cylinder test results following NPC transplantation demonstrate restored function in the affected forelimb.

\section{The walking test}

Brain subcortical and spinal cord networks mediate walking, and any alterations to these structures are known to impact walking performance. Several gait parameters were assessed to determine functional recovery following NPC transplantation. Here we present 1) swing speed (Fig. 10C,D), which is the speed of the paw while not in contact with the floor; 2) stride length (Fig. 10E,F), which is the distance between successive points of contact of the same paw; and 3) paw intensity (Fig. 10G,H), reflecting how the injury affects weight.

At baseline, the left/injured forelimb (LF) showed significant differences (2-way ANOVA, followed by Bonferroni's test) in swing speed $(33.19 \pm 0.71 \mathrm{~cm} / \mathrm{s}, F(2,247)=$ 402.50), stride length $(4.68 \pm 0.11 \mathrm{~cm}, F(2,247)=73.50)$, and paw intensity $(50.62 \pm 0.59$ intensity level $0-255, F(2$, $247)=581.30)$, compared to the left forelimb of the respective sham animals values $(45.54 \pm 0.84 \mathrm{~cm} / \mathrm{s}, p<$ $0.0001, t=4.43 ; 5.70 \pm 0.32 \mathrm{~cm}, p=0.0012, t=3.60$; and $73.28 \pm 2.19, p<0.0001, t=13.43$ ).

Following NPC transplantation, all 3 parameters showed recovery starting as early as 1 week after transplantation: swing speed $(\mathrm{HI}+\mathrm{NPC} 39.53 \pm 1.48 \mathrm{~cm} / \mathrm{s}$ versus sham $51.27 \pm 0.90 \mathrm{~cm} / \mathrm{s}, p<0.0027, t=3.36)$, stride length $(5.15 \pm 0.13 \mathrm{~cm}$ versus $6.04 \pm 0.23 \mathrm{~cm}, p<$ $0.0391, t=2.50)$, and paw intensity $(60.14 \pm 0.70$ versus $76.76 \pm 1.52, p<0.0001, t=7.86$ ).

After 9 weeks, there were no differences between $\mathrm{HI}+$ NPC and control groups in swing speed $(73.76 \pm 1.66$ $\mathrm{cm} / \mathrm{s}$ versus $78.06 \pm 2.15 \mathrm{~cm} / \mathrm{s}, p=0.6604, t=1.23)$, stride length $(6.34 \pm 0.14 \mathrm{~cm}$ versus $6.77 \pm 0.48 \mathrm{~cm}, p=$ $0.6840, t=1.21)$ and paw intensity (100.46 \pm 1.29 vs $102.81 \pm 2.39, p=0.8029, t=1.11$; Fig. $10 C, E, G)$. The lack of differences between the sham and HI + NPC groups at 9 weeks indicates a return of function to the left/injured forelimb of $\mathrm{HI}$ injured mice following transplantation of NPCs.

Similarly, the ratios of left/right forelimb values highlight the unilaterality of this functional impairment within each animal. Swing speed, stride length, and paw intensity ratios all showed significant impairment compared to sham animals, and these impairments were observed to disappear following NPC transplantation (Fig. 10D,F,H).
Results from the gait analysis demonstrate that the transplanted NPCs contribute to functional recovery.

\section{Discussion}

In this study, we first validated a hemiplegic neonatal hypoxia-ischemia model producing mild lesions, resulting in structural injury in various brain regions (e.g. cortex, hippocampus, CC) along with functional impairment. After NPC transplantation, partial structural recovery (of the cortex, lateral ventricle, and hippocampus) as well as full recovery (of the $\mathrm{CC}$ ) were observed. We propose that the repair induced by exogenous NPCs is a nondirect effect involving the recruitment of endogenous oligodendrocytes to the lesioned site, leading to white matter repair.

\section{Our HI model mimics the clinical features of cerebral palsy}

We generated a mild model of $\mathrm{HI}$ that displays pathobiological similarities to CP. One of the central features of CP pathology is WM injury, characterised here by the lesions observed in the CC. In addition, we observed in the ipsilateral/injured side a ventriculomegaly and an overall size reduction of the cortex, the hippocampus, and the brain hemisphere, which are consistent with past studies (Lubics et al., 2005; Lodygensky et al., 2010; Fatemi et al., 2011). Corroborating our data, clinical reports demonstrate that children with PVL exhibit an enlargement of the lateral ventricle (Davatzikos et al., 2003; Panigrahy et al., 2005), while periventricular regions, including WM, show structural and cellular abnormalities (Volpe, 2001, 2009b; Khwaja and Volpe, 2008).

The $\mathrm{CC}$ volume following $\mathrm{HI}$ decreased by an average of $36 \%$ and was in line with findings in previous neonatal animal studies (Sheldon et al., 1996; Skoff et al., 2001; Fatemi et al., 2011; Shrivastava et al., 2012). In many cases, the CC was found to be smaller in children with CP (Davatzikos et al., 2003; Panigrahy et al., 2005; Kulak et al., 2007; Ho et al., 2013; Andronikou et al., 2015).

The dysgenesis of the CC can be explained by the reduction of the OL population following injury and, specifically, by the significant decrease of mature OLs due to maturation arrest of the progenitors (Back et al., 2002; Segovia et al., 2008; Buser et al., 2010). The subsequent myelination impairment, due to reduced numbers of mature OLs, was confirmed by our histology (structural impairment, fewer mature OLs) and our electrophysiology data (functional impairment). Our findings showing reduced OLs and mature OLs are in line with clinical data, which confirm OL maturation disruption in children with CP (Buser et al., 2012; Back and Miller, 2014; Back, 2017). We demonstrated an association between CC impairment following $\mathrm{HI}$ and motor deficiencies. This is congruent 


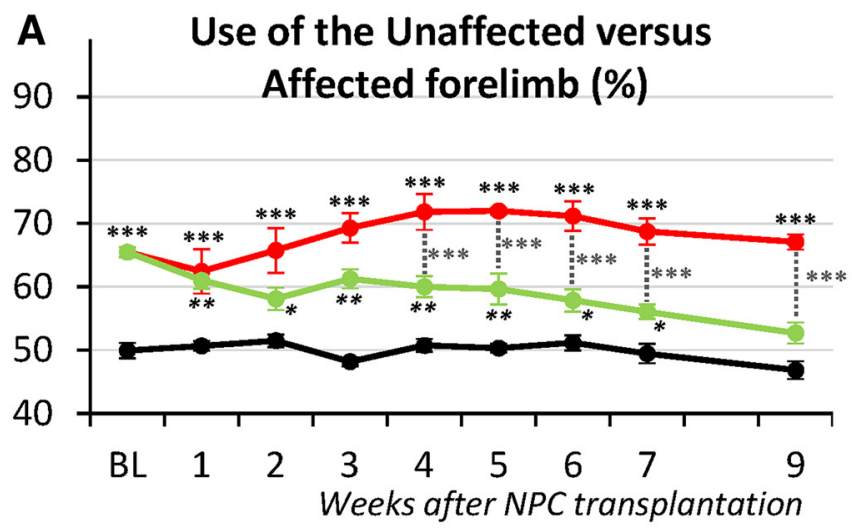

C LF - Swing speed $(\mathrm{cm} / \mathrm{s})$

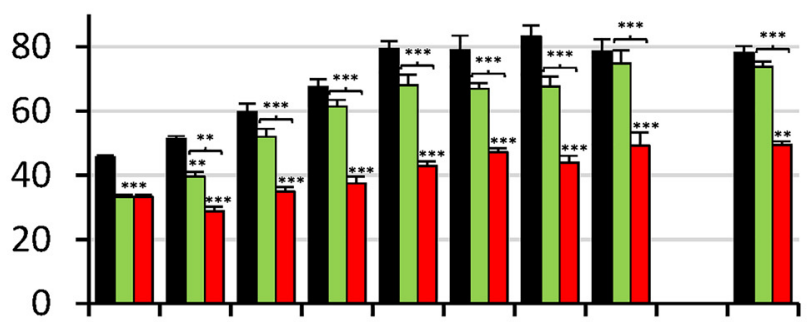

$\begin{array}{llllllllll}\mathrm{BL} & 1 & 2 & 3 & 4 & 5 & 6 & 7 & 8 & 9\end{array}$ Weeks after NPC transplantation

E

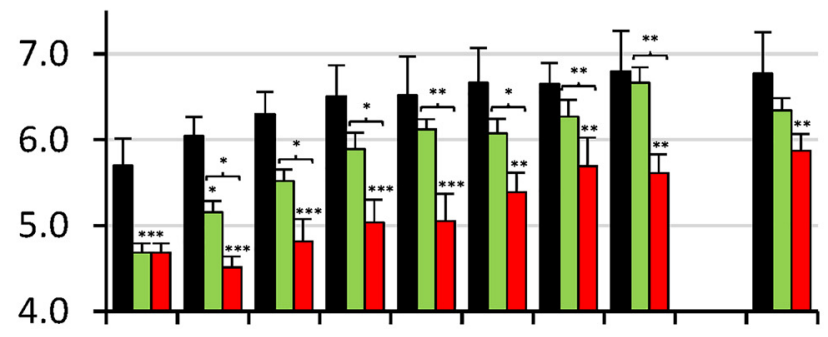

$\begin{array}{llllllllll}\mathrm{BL} & 1 & 2 & 3 & 4 & 5 & 6 & 7 & 8 & 9\end{array}$ Weeks after NPC transplantation

G LF - Max Contact Mean Intensity

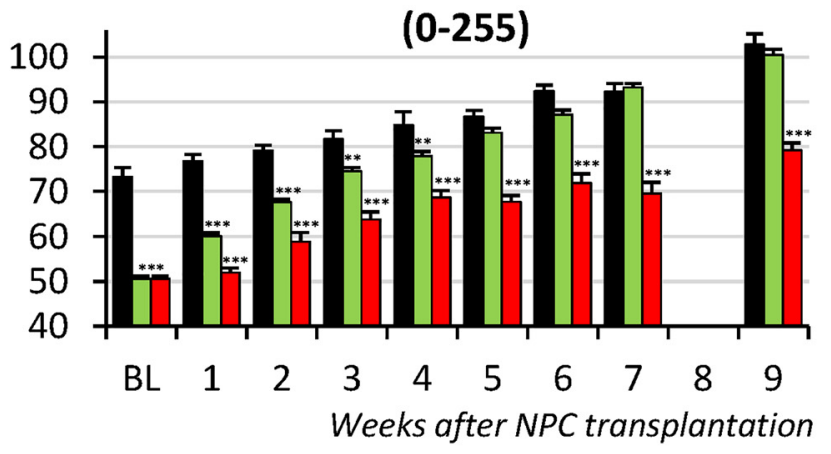

Sham

$\mathrm{HI}+\mathrm{NPC}$

HI + Vehicle
B

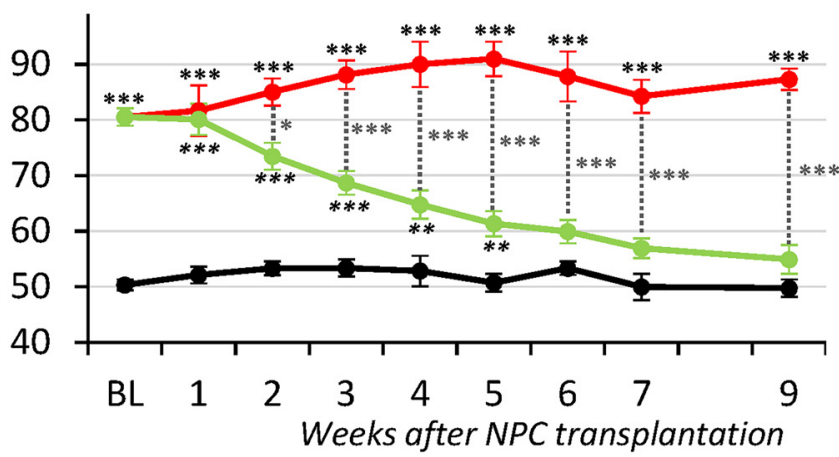

D

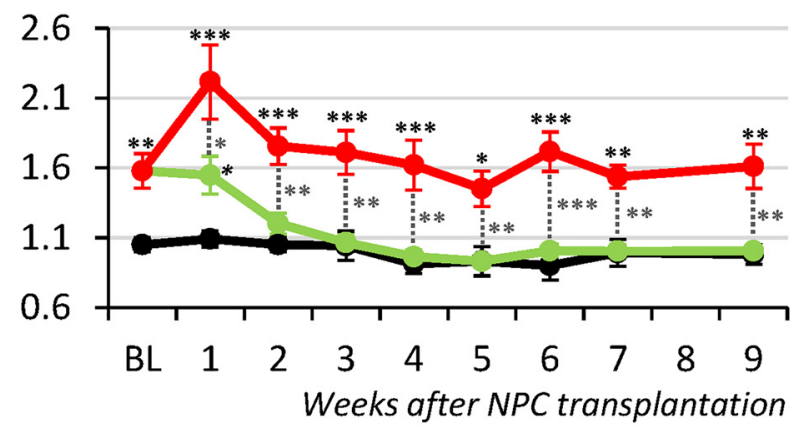

$\mathbf{F}$

1.4
1.3
1.2
1.1
1.0
0.9
0.8

Ratio RF/LF Stride Length

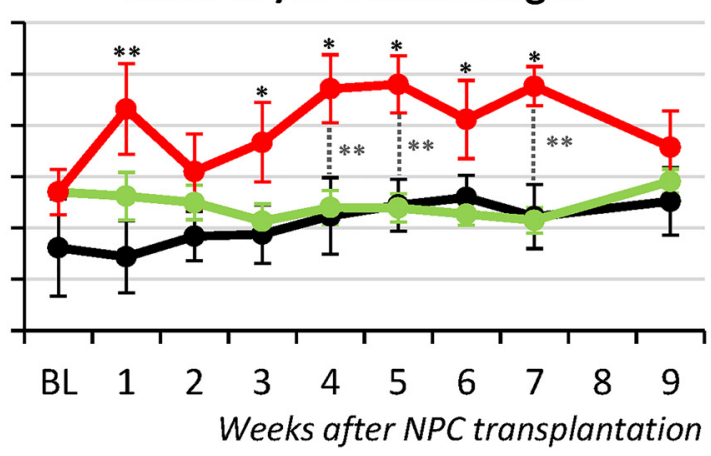

H

Ratio RF/LF LF Max Contact Mean Intensity (0-255)

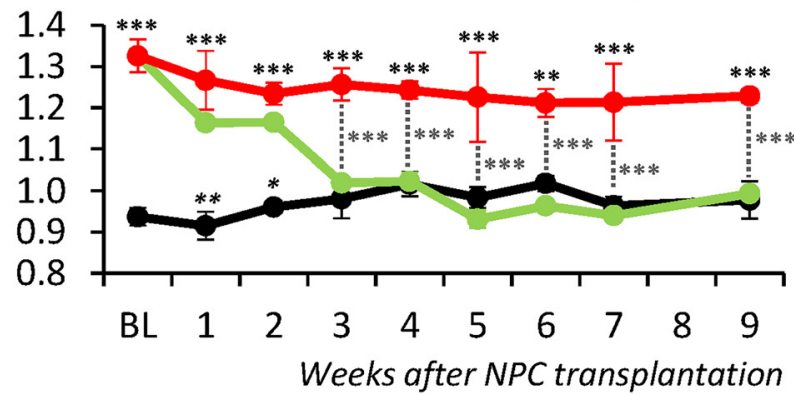

Sham $\mathrm{HI}+\mathrm{NPC} \quad \mathrm{HI}+$ Vehicle

Figure 10. Transplanted NPCs improve functional recovery (cylinder test; gait analysis - CatWalkXT). A, The HI mice used the unaffected right forelimb with a clear preference (cylinder test): the total use of the unaffected forelimb showed a clear unilateral impairment after $\mathrm{HI}$ injury. $\boldsymbol{A}$, The frequency at which the unaffected forelimb was used to start a rearing sequence also showed impairment. The NPC transplantation, as opposed to vehicle injection, led to functional recovery. $\boldsymbol{C}-\boldsymbol{H}$, The HI mice showed significant 
continued

impairment in several gait parameters such as swing speed $(\boldsymbol{C}, \boldsymbol{D})$, stride length $(\boldsymbol{E}, \boldsymbol{F})$, and paw intensity $(\boldsymbol{G}, \boldsymbol{H})$ which were corrected after NPC transplantation. $\boldsymbol{C}, \boldsymbol{E}$, and $\boldsymbol{G}$ compare the left forelimb between groups, while $\boldsymbol{D}, \boldsymbol{F}$, and $\boldsymbol{H}$ compare the left versus right forelimb of each animals (ratio). $\mathrm{BL}=$ baseline. $* p<0.05, * * p<0.01, * * * p<0.001$.

with MRI studies that demonstrate a correlation between WM injury and severity of motor and cognitive impairment in children with CP (Panigrahy et al., 2005; Woodward et al., 2006; Skranes et al., 2007; Hollund et al., 2018). Furthermore, a negative relationship between the CC area and the Gross Motor Function Classification System has been observed (Kulak et al., 2007), confirming a link between the CC and motor function. Here, we demonstrated significant motor deficiencies using behavioral testing, which has previously been reported in similar animal models (van der Kooij et al., 2010; Braccioli et al., 2017). These impairments are in line with gait abnormalities observed in children with CP (Wren et al., 2005; Fonseca et al., 2018; Zhou et al., 2017; Davids et al., 2018; Mutoh et al., 2018). Taken together, these results demonstrate that our model reliably reproduces clinical features of $\mathrm{CP}$.

\section{Transplanted NPCs survive, migrate, engraft, and morphologically differentiate in the corpus callosum}

Following transplantation, we observed an NPC survival rate $(\sim 4.5 \%)$ similar to those reported in a recent study from our lab (6.3\%; Ruff et al., 2013b). Despite this low survival rate, we observed a significant effect on motor recovery. Interestingly, survival as low as $1 \%$ has been shown to be suitable for WM repair after spinal cord injury (Bottai et al., 2010).

The NPCs migrated and spread through the CC and reached the injured periventricular area. Interestingly, NPCs transplanted only in the left/uninjured CC migrated toward the right/injured $\mathrm{CC}$ and crossed the midline (data not shown). OLs/OL progenitors are known to migrate toward the site of brain injury (Gensert and Goldman, 1997; NaitOumesmar et al., 1999; Yandava et al., 1999; Skoff et al., 2001; Dizon et al., 2010; Obenaus et al., 2011).

NPCs have the potential to differentiate into OLs, neurons, and astrocytes in vitro (Karimi-Abdolrezaee et al., 2006; Eftekharpour et al., 2007). The differentiation profile observed here (OLs < 2\%) was different than those reported in our previous studies: $97 \%$ of OLs in the uninjured shiverer mouse brain (Ruff et al., 2013b) and 80\% in the spinal cord (Karimi-Abdolrezaee et al., 2010). Here we show that most of the transplanted NPCs remained positive for Nestin, a neural stem cell marker (Bernal and Arranz, 2018), suggesting that they have retained some NPC properties. We suggest that the specific in vivo heterogeneous microenvironment of the host tissue could explain this discrepancy.

However, the NPCs were anatomically well engrafted in the CC, where they differentiated morphologically, changing from a spherical to a fibroblast-like shape. While the transplanted NPCs did not notably colonize the neighboring structures, they grew numerous projections toward the cortex or the hippocampus. These morphologic changes suggest specific mechanisms of integration, with potential connections being made with the surrounding tissue via adhesion molecules, trophic factor release, or electrophysiological interactions (Nait-Oumesmar et al., 1999; Carmichael, 2003; Overman and Carmichael, 2014). Further, this engraftment is consistent with the "bio-bridge" concept, which relies on the establishment of a connecting framework by the transplanted stem cells between the lesioned site and the neurogenic subependymal zone (Sullivan et al., 2015; Lee et al., 2017; Liska et al., 2017). The endogenous cells involved in the repair process are recruited and guided by this bridge toward the injury site. Interestingly, once the bio-bridge is functional, the transplanted stem cells can disappear (Tajiri et al., 2013).

\section{Transplanted NPCs trigger cellular changes and result in structural recovery and functional improvement}

Although the transplanted NPCs produced an effect on the ipsilateral/injured brain hemisphere and hippocampus, they failed to fully counteract the size decrease that arose after $\mathrm{HI}$ injury. Nevertheless, the ipsilateral ventriculomegaly was mostly restored, while the structural integrity of the CC was fully repaired. Likewise, after NPC transplantation in the $\mathrm{CC}$, the $\mathrm{OL}$ population was restored and even increased above the normal level, as defined by the level of the contralateral side or the ipsilateral side of control mice, while the percentage of mature OLs was normalized. Furthermore, the lack of YFP staining of these cells confirms their endogenous origin.

In the dysmyelinated shiverer mouse, we have previously shown that NPCs differentiated to OLs at a rate of $97 \%$ and resulted in myelination (Ruff et al., 2013b). Here, by electrophysiology, we also demonstrated myelination of the unmyelinated axons of the injured CC. However, this appears to be performed by endogenous OLs attracted to the lesioned area by the Nestin-positive transplanted NPCs. The involvement of endogenous progenitors in myelination following a demyelinating injury is well established (Gensert and Goldman, 1997; Hawryluk et al., 2014; Buono et al., 2015), with precursors predominantly originating from subependymal zone cells, migrating toward the lesion site, and differentiating into OLs (Nait-Oumesmar et al., 1999; Etxeberria et al., 2010; van Tilborg et al., 2018). Alternatively, it has been proposed that endogenous OLs act locally, originating from the cortex or the striatum, with limited involvement from the subventricular zone (Dizon et al., 2010).

Our electrophysiology data confirmed that the CC myelination observed after NPC transplantation was functional. This corroborates the motor improvements posttransplantation observed in behavior testing, which showed a clear return of function for the impaired forelimb. This improvement following WM repair can be explained by the fact that the callosal motor fibers connecting the primary motor cortices of both hemispheres are central for bimanual coordination and learning of bimanual motor skill. Therefore, motor impairment following $\mathrm{HI}$ is likely due to a disconnection of 
the cortex from the midbrain, brainstem, and spinal cord following subcortical damage to descending fiber tracts and/or direct damage to the motor cortex (Clowry et al., 2014). For example, spastic CP is primarily a lesion of the corticospinal tract leading to secondary aberrant developments and the reorganization of movement and somatosensory cortical representations in the injured hemisphere (Jones and Adkins, 2015).

The white matter repair we have demonstrated here, as well as the functional myelination and the significant motor recovery, is most likely triggered by the increased endogenous OL population observed in the CC $(+220 \%$ when comparing treated and untreated groups), resulting from a recruitment mediated/amplified by the transplanted exogenous NPCs. Interestingly, at the lesion site we have demonstrated glial scar formation, which is a dense structure consisting of hyperproliferative astrocytes that impede tissue regeneration (Khazaei et al., 2016; Ahuja et al., 2017). The reduction of the glial scar following NPC transplantation is likely to lower its inhibitive properties regarding regeneration and facilitate the migration of recruited endogenous cells for repair.

NPC survival rates as low as $1 \%$ have been previously shown to have an effect on WM repair (Bottai et al., 2010), supporting a nondirect effect mechanism involving a biobridge and/or trophic effect. Interestingly, NPCs are known to express molecules (e.g., platelet-derived growth factor(PDGF) $\alpha$, insulin-like growth factor (IGF)-1, brain-derived neurotrophic factor (BDNF), and erythropoietin (EPO) that are fundamental to oligodendrogenesis (Chicha et al., 2014; Buono et al., 2015; Yu et al., 2016) and could also improve brain repair via immunomodulation (Kokaia et al., 2012). Further, our lab has shown that in vivo transplantation of NPCs produces significantly higher levels of trophins such as IGF-1, nerve growth factor (NGF), leukemia inhibitory factor (LIF), ciliary neurotrophic factor (CNTF), epidermal growth factor (EGF), basic fibroblast growth factor (bFGF), and transforming growth factor (TGF)- $\beta 1$, while lowering the expression of PDGF- $\alpha$ and vascular endothelial growth factor isoform (VEGF)- $\alpha$ (Hawryluk et al., 2012). These alterations demonstrate the environmental influence on the functioning of the NPC in vivo.

Taken together, the data presented here support the hypothesis that endogenous cells produce regenerative effects when triggered by exogenous NPCs (Dibajnia and Morshead, 2013; Dadwal et al., 2015; Yu et al., 2016; Ruddy and Morshead, 2018).

\section{Conclusion}

Our model of mild, yet functionally significant, injury exhibits a pattern of lesions that is comparable with many aspects of clinical CP. We demonstrated that NPCs transplanted in the CC play a crucial role in recovery through the reduction of glial scarring and the attraction of endogenous oligodendrocytes, probably via a bio-bridge and/or trophic support. The WM repair observed here involves myelination. Future studies are needed to determine the origin of the recruited endogenous oligodendrocytes, as well as the potential trophic factors released by NPCs, and their cellular targets to further decipher the mechanisms underlying the recovery.

Note Added in Proof: The 7th author, Mohamad Khazaei, was incorrectly omitted from the list of authors in the Early Release version published October 22, 2018. The list of authors and author contributions has now been corrected in the copyedited version of the article.

\section{References}

Ahuja CS, Wilson JR, Nori S, Kotter MRN, Druschel C, Curt A, Fehlings MG (2017) Traumatic spinal cord injury. Nat Rev Dis Primers 3:17018. CrossRef Medline

Andronikou S, Pillay T, Gabuza L, Mahomed N, Naidoo J, Hlabangana LT, Du Plessis V, Prabhu SP (2015) Corpus callosum thickness in children: an MR pattern-recognition approach on the midsagittal image. Pediatr Radiol 45:258-272. CrossRef

Back SA, Han BH, Luo NL, Chricton CA, Xanthoudakis S, Tam J, Arvin KL, Holtzman DM (2002) Selective vulnerability of late oligodendrocyte progenitors to hypoxia-ischemia. J Neurosci 22:455463. CrossRef

Back SA, Miller SP (2014) Brain injury in premature neonates: A primary cerebral dysmaturation disorder? Ann Neurol 75:469-486. CrossRef Medline

Back SA (2017) White matter injury in the preterm infant: pathology and mechanisms. Acta Neuropathol 134:331-349. CrossRef Medline

Balduini W, De Angelis V, Mazzoni E, Cimino M (2000) Long-lasting behavioral alterations following a hypoxic/ischemic brain injury in neonatal rats. Brain Res 859:318-325. Medline

Bernal A, Arranz L (2018) Nestin-expressing progenitor cells: function, identity and therapeutic implications. Cell Mol Life Sci 75: 2177-2195.

Bottai D, Cigognini D, Madaschi L, Adami R, Nicora E, Menarini M, Di Giulio AM, Gorio A (2010) Embryonic stem cells promote motor recovery and affect inflammatory cell infiltration in spinal cord injured mice. Exp Neurol 223:452-463. CrossRef Medline

Braccioli L, Heijnen CJ, Coffer PJ, Nijboer CH (2017) Delayed administration of neural stem cells after hypoxia-ischemia reduces sensorimotor deficits, cerebral lesion size, and neuroinflammation in neonatal mice. Pediatr Res 81:127-135. CrossRef Medline

Buono KD, Goodus MT, Guardia Clausi M, Jiang Y, Loporchio D, Levison SW (2015) Mechanisms of mouse neural precursor expansion after neonatal hypoxia-ischemia. J Neurosci 35:8855-8865. CrossRef

Buser JR, Segovia KN, Dean JM, Nelson K, Beardsley D, Gong X, Luo NL, Ren J, Wan Y, Riddle A, McClure MM, Ji X, Derrick M, Hohimer AR, Back SA, Tan S (2010) Timing of appearance of late oligodendrocyte progenitors coincides with enhanced susceptibility of preterm rabbit cerebral white matter to hypoxia-ischemia. $J$ Cereb Blood Flow Metab 30:1053-1065. CrossRef Medline

Buser JR, Maire J, Riddle A, Gong X, Nguyen T, Nelson K, Luo NL, Ren J, Struve J, Sherman LS, Miller SP, Chau V, Hendson G, Ballabh P, Grafe MR, Back SA (2012) Arrested preoligodendrocyte maturation contributes to myelination failure in premature infants. Ann Neurol 71:93-109. CrossRef Medline

Carmichael ST (2003) Plasticity of cortical projections after stroke. Neuroscientist 9:64-75. CrossRef

Chen H, Burris M, Fajilan A, Spagnoli F, Tang J, Zhang JH (2011) Prolonged exposure to isoflurane ameliorates infarction severity in the rat pup model of neonatal hypoxia-ischemia. Translat Stroke Res 2:382-390. CrossRef Medline

Chen H, Du J, Zhang Y, Barnes K, Jia X (2017) Establishing a reliable gait evaluation method for rodent studies. J Neurosci Methods 283:92-100.

Chicha L, Smith T, Guzman R (2014) Stem cells for brain repair in neonatal hypoxia-ischemia. Childs Nerv Syst 30:37-46. CrossRef Medline 
Clowry GJ, Basuodan R, Chan F (2014) What are the best animal models for testing early intervention in cerebral palsy? Front Neurol 5:258. CrossRef Medline

Colver A, Fairhurst C, Pharoah PO (2014) Cerebral palsy. Lancet 383:1240-1249. CrossRef Medline

Coq JO, Delcour M, Massicotte VS, Baud O, Barbe MF (2016) Prenatal ischemia deteriorates white matter, brain organization, and function: implications for prematurity and cerebral palsy. Dev Med Child Neurol 58: 7-11. CrossRef

Dadwal P, Mahmud N, Sinai L, Azimi A, Fatt M, Wondisford FE, Miller FD, Morshead CM (2015) Activating endogenous neural precursor cells using metformin leads to neural repair and functional recovery in a model of childhood brain injury. Stem Cell Rep 5:166-173. CrossRef

Davatzikos C, Barzi A, Lawrie T, Hoon AH, Jr., Melhem ER (2003) Correlation of corpus callosal morphometry with cognitive and motor function in periventricular leukomalacia. Neuropediatrics 34:247-252.

Davids JR, Cung NQ, Pomeroy R, Schultz B, Torburn L, Kulkarni VA, Brown S, Bagley AM (2018) Quantitative assessment of knee progression angle during gait in children with cerebral palsy. $J$ Pediatr Orthop 38:e219-e224.

De Reuck J (1971) The human periventricular arterial blood supply and the anatomy of cerebral infarctions. Eur Neurol 5:321-334. CrossRef Medline

Dibajnia P, Morshead CM (2013) Role of neural precursor cells in promoting repair following stroke. Acta Pharmacol Sin 34:78-90. CrossRef Medline

Dizon M, Szele F, Kessler JA (2010) Hypoxia-ischemia induces an endogenous reparative response by local neural progenitors in the postnatal mouse telencephalon. Dev Neurosci 32:173-183. CrossRef Medline

Eftekharpour E, Karimi-Abdolrezaee S, Wang J, El Beheiry H, Morshead C, Fehlings MG (2007) Myelination of congenitally dysmyelinated spinal cord axons by adult neural precursor cells results in formation of nodes of Ranvier and improved axonal conduction. J Neurosci 27:3416-3428. CrossRef

Etxeberria A, Mangin JM, Aguirre A, Gallo V (2010) Adult-born SVZ progenitors receive transient synapses during remyelination in corpus callosum. Nat Neurosci 13:287-289. CrossRef Medline

Fatemi A, Wilson MA, Phillips AW, McMahon MT, Zhang J, Smith SA, Arauz EJ, Falahati S, Gummadavelli A, Bodagala H, Mori S, Johnston MV (2011) In vivo magnetization transfer MRI shows dysmyelination in an ischemic mouse model of periventricular leukomalacia. J Cereb Blood Flow Metab 31:2009-2018. CrossRef

Faulkner SD, Ruff CA, Fehlings MG (2013) The potential for stem cells in cerebral palsy-piecing together the puzzle. Semin Pediatr Neurol 20:146-153. CrossRef Medline

Fonseca PR, Jr., Franco de Moura RC, Galli M, Santos Oliveira C (2018) Effect of physiotherapeutic intervention on the gait after the application of botulinum toxin in children with cerebral palsy: systematic review. Eur J Phys Rehab Med 54:757-765.

Gensert JM, Goldman JE (1997) Endogenous progenitors remyelinate demyelinated axons in the adult CNS. Neuron 19:197-203. CrossRef

Goto N (1987) Discriminative staining methods for the nervous system: luxol fast blue-periodic acid-Schiff-hematoxylin triple stain and subsidiary staining methods. Stain Technology 62:305-315. Medline

Graham HK, Rosenbaum P, Paneth N, Dan B, Lin JP, Damiano DL, Becher JG, Gaebler-Spira D, Colver A, Reddihough DS, Crompton KE, Lieber RL (2016) Cerebral palsy. Nat Rev Dis Primers 2:15082. CrossRef Medline

Hagberg H, Mallard C, Ferriero DM, Vannucci SJ, Levison SW, Vexler ZS, Gressens P (2015) The role of inflammation in perinatal brain injury. Nat Rev Neurol 11:192-208. CrossRef Medline

Hawryluk GWJ, Mothe A, Wang J, Wang S, Tator C, Fehlings MG (2012) An in vivo characterization of trophic factor production following neural precursor cell or bone marrow stromal cell transplantation for spinal cord injury. Stem Cells Dev 21:2222-2238. CrossRef Medline

Hawryluk GW, Spano S, Chew D, Wang S, Erwin M, Chamankhah M, Forgione N, Fehlings MG (2014) An examination of the mecha- nisms by which neural precursors augment recovery following spinal cord injury: a key role for remyelination. Cell Transplant 23:365-380. CrossRef Medline

Ho ML, Moonis G, Ginat DT, Eisenberg RL (2013) Lesions of the corpus callosum. Am J Roentgenol 200:W1-16. CrossRef Medline Hollund IMH, Olsen A, Skranes J, Brubakk AM, Håberg AK, Eikenes L, Evensen KAI (2018) White matter alterations and their associations with motor function in young adults born preterm with very low birth weight. Neuroimage Clin 17:241-250. CrossRef Medline Johnson HJ, McCormick MM, Ibanez L, Consortium IS (2017) The ITK Software Guide - Book 1: Introduction and Development Guidelines, 4th Ed., version 4.11. Kitware, Inc., Available at https:// itk.org.

Johnston MV, Ferriero DM, Vannucci SJ, Hagberg H (2005) Models of cerebral palsy: which ones are best?. J Child Neurol 20:984987. CrossRef Medline

Jones TA, Adkins DL (2015) Motor system reorganization after stroke: stimulating and training toward perfection. Physiology 30 : 358-370. CrossRef Medline

Karimi-Abdolrezaee S, Eftekharpour E, Wang J, Morshead CM, Fehlings MG (2006) Delayed transplantation of adult neural precursor cells promotes remyelination and functional neurological recovery after spinal cord injury. J Neurosci 26:3377-3389. CrossRef

Karimi-Abdolrezaee S, Eftekharpour E, Wang J, Schut D, Fehlings MG (2010) Synergistic effects of transplanted adult neural stem/ progenitor cells, chondroitinase, and growth factors promote functional repair and plasticity of the chronically injured spinal cord. $J$ Neurosci 30:1657-1676. CrossRef

Khazaei M, Ahuja CS, Fehlings MG (2016) Induced pluripotent stem cells for traumatic spinal cord injury. Front Cell Dev Biol 4:152. CrossRef Medline

Khwaja O, Volpe JJ (2008) Pathogenesis of cerebral white matter injury of prematurity. Arch Dis Child Fetal Neonatal Ed 93:F153F161. CrossRef Medline

Kokaia Z, Martino G, Schwartz M, Lindvall O (2012) Cross-talk between neural stem cells and immune cells: the key to better brain repair? Nat Neurosci 15:1078-1087. CrossRef Medline

Kulak W, Sobaniec W, Kubas B, Walecki J (2007) Corpus callosum size in children with spastic cerebral palsy: relationship to clinical outcome. J Child Neurol 22:371-374. CrossRef Medline

Lee JY, Xu K, Nguyen H, Guedes VA, Borlongan CV, Acosta SA (2017) Stem cell-induced biobridges as possible tools to aid neuroreconstruction after CNS injury. Front Cell Dev Biol 5:51. CrossRef Medline

Li L, Velumian AA, Samoilova M, Fehlings MG (2016) A novel approach for studying the physiology and pathophysiology of myelinated and non-myelinated axons in the CNS white matter. PLoS One 11:e0165637. CrossRef Medline

Liska MG, Crowley MG, Nguyen H, Borlongan CV (2017) Biobridge concept in stem cell therapy for ischemic stroke. J Neurosurg Sci 61:173-179. CrossRef Medline

Lodygensky GA, Vasung L, Sizonenko SV, Hüppi PS (2010) Neuroimaging of cortical development and brain connectivity in human newborns and animal models. J Anat 217:418-428. CrossRef Medline

Lubics A, Reglodi D, Tamás A, Kiss P, Szalai M, Szalontay L, Lengvári I (2005) Neurological reflexes and early motor behavior in rats subjected to neonatal hypoxic-ischemic injury. Behavioural Brain Res 157:157-165. CrossRef Medline

McAdams RM, Juul SE (2016) Neonatal encephalopathy: update on therapeutic hypothermia and other novel therapeutics. Clin Perinatol 43:485-500. CrossRef Medline

McQuillen PS, Sheldon RA, Shatz CJ, Ferriero DM (2003) Selective vulnerability of subplate neurons after early neonatal hypoxiaischemia. J Neurosci 23:3308-3315. CrossRef

Mutoh T, Mutoh T, Tsubone H, Takada M, Doumura M, Ihara M, Shimomura H, Taki Y, Ihara M (2018) Impact of serial gait analyses on long-term outcome of hippotherapy in children and adoles- 
cents with cerebral palsy. Complement Ther Clin Pract 30:19-23. CrossRef

Nait-Oumesmar B, Decker L, Lachapelle F, Avellana-Adalid V, Bachelin C, Baron-Van Evercooren A (1999) Progenitor cells of the adult mouse subventricular zone proliferate, migrate and differentiate into oligodendrocytes after demyelination. Eur J Neurosci 11:4357-4366. Medline

Nyul LG, Udupa JK, Zhang X (2000) New variants of a method of MRI scale standardization. IEEE Transact Med Imaging 19:143-150. CrossRef Medline

Obenaus A, Dilmac N, Tone B, Tian HR, Hartman R, Digicaylioglu M, Snyder EY, Ashwal S (2011) Long-term magnetic resonance imaging of stem cells in neonatal ischemic injury. Ann Neurol 69:282291. CrossRef Medline

Okusa C, Oeschger F, Ginet V, Wang WZ, Hoerder-Suabedissen A, Matsuyama T, Truttmann AC, Molnár Z (2014) Subplate in a rat model of preterm hypoxia-ischemia. Ann Clin Translat Neurol 1:679-691. CrossRef

Overman JJ, Carmichael ST (2014) Plasticity in the injured brain: more than molecules matter. Neuroscientist 20:15-28. CrossRef

Palmer C, Vannucci RC, Towfighi J (1990) Reduction of perinatal hypoxic-ischemic brain damage with allopurinol. Pediatr Res 27: 332-336. CrossRef Medline

Panigrahy A, Barnes PD, Robertson RL, Sleeper LA, Sayre JW (2005) Quantitative analysis of the corpus callosum in children with cerebral palsy and developmental delay: correlation with cerebral white matter volume. Pediatr Radiol 35:1199-1207. CrossRef Medline

Paul LK, Brown WS, Adolphs R, Tyszka JM, Richards LJ, Mukherjee P, Sherr EH (2007) Agenesis of the corpus callosum: genetic, developmental and functional aspects of connectivity. Nat Rev Neurosci 8:287-299. CrossRef Medline

Rice JE, 3rd, Vannucci RC, Brierley JB (1981) The influence of immaturity on hypoxic-ischemic brain damage in the rat. Ann Neurol 9:131-141. CrossRef

Richards LJ, Plachez C, Ren T (2004) Mechanisms regulating the development of the corpus callosum and its agenesis in mouse and human. Clin Genet 66:276-289. CrossRef Medline

Ruddy RM, Morshead CM (2018) Home sweet home: the neural stem cell niche throughout development and after injury. Cell Tissue Res 371:125-141. CrossRef Medline

Ruff CA, Faulkner SD, Fehlings MG (2013a) The potential for stem cell therapies to have an impact on cerebral palsy: opportunities and limitations. Dev Med Child Neurol 55:689-697.

Ruff CA, Ye H, Legasto JM, Stribbell NA, Wang J, Zhang L, Fehlings MG (2013b) Effects of adult neural precursor-derived myelination on axonal function in the perinatal congenitally dysmyelinated brain: optimizing time of intervention, developing accurate prediction models, and enhancing performance. J Neurosci 33:1189911915. CrossRef

Rumajogee P, Bregman T, Miller SP, Yager JY, Fehlings MG (2016) Rodent hypoxia-ischemia models for cerebral palsy research: a systematic review. Front Neurol 7:57. CrossRef Medline

Sampaio-Baptista C, Johansen-Berg H (2017) White matter plasticity in the adult brain. Neuron 96:1239-1251. CrossRef Medline

Segovia KN, McClure M, Moravec M, Luo NL, Wan Y, Gong X, Riddle A, Craig A, Struve J, Sherman LS, Back SA (2008) Arrested oligodendrocyte lineage maturation in chronic perinatal white matter injury. Ann Neurol 63:520-530. CrossRef Medline

Semple BD, Blomgren K, Gimlin K, Ferriero DM, Noble-Haeusslein LJ (2013) Brain development in rodents and humans: identifying benchmarks of maturation and vulnerability to injury across species. Progress Neurobiol 106-107:1-16. CrossRef Medline

Sethian JA, Sethian JA (1999) Level set methods and fast marching methods: evolving interfaces in computational geometry, fluid mechanics, computer vision, and materials science, 2nd Edition. Cambridge, UK: Cambridge University Press.

Sheldon RA, Chuai J, Ferriero DM (1996) A rat model for hypoxicischemic brain damage in very premature infants. Biol Neonate 69:327-341. CrossRef Medline
Shrivastava K, Chertoff M, Llovera G, Recasens M, Acarin L (2012) Short and long-term analysis and comparison of neurodegeneration and inflammatory cell response in the ipsilateral and contralateral hemisphere of the neonatal mouse brain after hypoxia/ ischemia. Neurol Res Int 2012:781512. CrossRef

Skoff RP, Bessert DA, Barks JD, Song D, Cerghet M, Silverstein FS (2001) Hypoxic-ischemic injury results in acute disruption of myelin gene expression and death of oligodendroglial precursors in neonatal mice. Int J Dev Neurosci 19:197-208. CrossRef

Skranes J, Vangberg TR, Kulseng S, Indredavik MS, Evensen KA, Martinussen M, Dale AM, Haraldseth O, Brubakk AM (2007) Clinical findings and white matter abnormalities seen on diffusion tensor imaging in adolescents with very low birth weight. Brain 130:654-666. CrossRef Medline

Sullivan R, Duncan K, Dailey T, Kaneko Y, Tajiri N, Borlongan CV (2015) A possible new focus for stroke treatment - migrating stem cells. Exp Opin Biol Ther 15:949-958. CrossRef Medline

Tajiri N, Kaneko Y, Shinozuka K, Ishikawa H, Yankee E, McGrogan M, Case C, Borlongan CV (2013) Stem cell recruitment of newly formed host cells via a successful seduction? Filling the gap between neurogenic niche and injured brain site. PLoS One 8:e74857. CrossRef

Thoresen M (2015) Who should we cool after perinatal asphyxia? Semin Fetal Neonatal Med 20:66-71. CrossRef Medline

Tropepe V, Sibilia M, Ciruna BG, Rossant J, Wagner EF, van der Kooy D (1999) Distinct neural stem cells proliferate in response to EGF and FGF in the developing mouse telencephalon. Dev Biol 208:166-188. CrossRef Medline

Tustison NJ, Avants BB, Cook PA, Zheng Y, Egan A, Yushkevich PA, Gee JC (2010) N4ITK: improved N3 bias correction. IEEE Transact Med Imaging 29:1310-1320. CrossRef Medline

van der Kooij MA, OhI F, Arndt SS, Kavelaars A, van Bel F, Heijnen CJ (2010) Mild neonatal hypoxia-ischemia induces long-term motorand cognitive impairments in mice. Brain Behav Immun 24:850856. CrossRef Medline

van Tilborg E, de Theije CGM, van Hal M, Wagenaar N, de Vries LS, Benders MJ, Rowitch DH, Nijboer CH (2018) Origin and dynamics of oligodendrocytes in the developing brain: Implications for perinatal white matter injury. Glia 66:221-238. CrossRef Medline

Vannucci RC, Vannucci SJ (2005) Perinatal hypoxic-ischemic brain damage: evolution of an animal model. Dev Neurosci 27:81-86. CrossRef Medline

Volpe JJ (2001) Neurobiology of periventricular leukomalacia in the premature infant. Pediatr Res 50:553-562. CrossRef Medline

Volpe JJ (2009a) The encephalopathy of prematurity-brain injury and impaired brain development inextricably intertwined. Semin Pediatr Neurol 16:167-178. CrossRef

Volpe JJ (2009b) Brain injury in premature infants: a complex amalgam of destructive and developmental disturbances. Lancet Neurol 8:110-124. CrossRef

Woodward LJ, Anderson PJ, Austin NC, Howard K, Inder TE (2006) Neonatal MRI to predict neurodevelopmental outcomes in preterm infants. N Engl J Med 355:685-694. CrossRef Medline

Wren TA, Rethlefsen S, Kay RM (2005) Prevalence of specific gait abnormalities in children with cerebral palsy: influence of cerebral palsy subtype, age, and previous surgery. J Pediatr Orthop 25:79_ 83. Medline

Yandava BD, Billinghurst LL, Snyder EY (1999) "Global" cell replacement is feasible via neural stem cell transplantation: evidence from the dysmyelinated shiverer mouse brain. Proc Natl Acad Sci USA 96:7029-7034. Medline

Yu JH, Seo JH, Lee JY, Lee MY, Cho SR (2016) Induction of neurorestoration from endogenous stem cells. Cell Transplant 25: 863-882. CrossRef Medline

Zhou J, Butler EE, Rose J (2017) Neurologic correlates of gait abnormalities in cerebral palsy: implications for treatment. Front Hum Neurosci 11:103. CrossRef Medline 